\title{
Sulfidic Anion Concentrations on Early Earth for Surficial Origins-of-Life Chemistry
}

\author{
Sukrit Ranjan,, ${ }^{1,2}$ Zoe R. Todd, ${ }^{1}$ John D. Sutherland, ${ }^{3}$ and Dimitar D. Sasselov ${ }^{1}$
}

\begin{abstract}
A key challenge in origin-of-life studies is understanding the environmental conditions on early Earth under which abiogenesis occurred. While some constraints do exist (e.g., zircon evidence for surface liquid water), relatively few constraints exist on the abundances of trace chemical species, which are relevant to assessing the plausibility and guiding the development of postulated prebiotic chemical pathways which depend on these species. In this work, we combine literature photochemistry models with simple equilibrium chemistry calculations to place constraints on the plausible range of concentrations of sulfidic anions $\left(\mathrm{HS}^{-}, \mathrm{HSO}_{3}{ }^{-}, \mathrm{SO}_{3}{ }^{2-}\right.$ ) available in surficial aquatic reservoirs on early Earth due to outgassing of $\mathrm{SO}_{2}$ and $\mathrm{H}_{2} \mathrm{~S}$ and their dissolution into small shallow surface water reservoirs like lakes. We find that this mechanism could have supplied prebiotically relevant levels of $\mathrm{SO}_{2}$-derived anions, but not $\mathrm{H}_{2} \mathrm{~S}$-derived anions. Radiative transfer modeling suggests UV light would have remained abundant on the planet surface for all but the largest volcanic explosions. We apply our results to the case study of the proposed prebiotic reaction network of Patel et al. (2015) and discuss the implications for improving its prebiotic plausibility. In general, epochs of moderately high volcanism could have been especially conducive to cyanosulfidic prebiotic chemistry. Our work can be similarly applied to assess and improve the prebiotic plausibility of other postulated surficial prebiotic chemistries that are sensitive to sulfidic anions, and our methods adapted to study other atmospherically derived trace species. Key Words: Early Earth-Origin of life-Prebiotic chemistry-Volcanism-UV radiation—Planetary environments. Astrobiology 18, 1023-1040.
\end{abstract}

\section{Introduction}

A KEY CHALLENGE for origins-of-life studies is determining the environmental conditions on early Earth. Environmental conditions (e.g., $\mathrm{pH}$, temperature, pressure, chemical feedstock abundance) play a major role in determining the kinds of prebiotic chemistry that are possible or probable, and hence can help constrain the plausibility of proposed origin-of-life scenarios (e.g., Urey, 1952; Corliss et al., 1981; McCollom, 2013; Ruiz-Mirazo et al., 2014). Consequently, it is critical to understand the range of environmental conditions available on early Earth for abiogenesis to proceed. Work over the past few decades has begun to constrain the environmental conditions that may have been available for abiogenesis, including but not limited to the past presence of liquid water, the availability of UV light at the surface, the mix of gases being outgassed to the atmosphere, the bulk $\mathrm{pH}$ of the ocean, and the conditions available at deep-sea hydrothermal vents (Bada et al., 1994; Farquhar et al., 2000; Delano, 2001; Holm and Charlou, 2001; Mojzsis et al., 2001; McCollom and Seewald, 2007; Trail et al., 2011; Mulkidjanian et al., 2012; Beckstead et al., 2016; Sojo et al., 2016; Halevy and Bachan, 2017; Novoselov et al., 2017; Ranjan and Sasselov, 2017).

One challenging environmental factor to constrain is the abundance of trace chemical species on early Earth. These species can be important to proposed prebiotic chemical pathways as feedstocks or catalysts, but their abundances on early Earth can be difficult to determine due to their rarity and hence limited impact on an already scarce rock record. In this paper, we explore the plausible abundances of one such family of molecules: sulfidic anions, that is, sulfur-bearing

\footnotetext{
${ }^{1}$ Harvard-Smithsonian Center for Astrophysics, Cambridge, Massachusetts, USA.

${ }^{2}$ MIT Department of Earth, Atmospheric, and Planetary Sciences, Cambridge, Massachusetts, USA.

${ }^{3}$ Medical Research Council Laboratory of Molecular Biology, Cambridge, UK.

(c) Sukrit Ranjan et al., 2018; Published by Mary Ann Liebert, Inc. This Open Access article is distributed under the terms of the Creative Commons License (http://creativecommons.org/licenses/by/4.0), which permits unrestricted use, distribution, and reproduction in any medium, provided the original work is properly credited.
} 
aqueous anions (e.g., hydrosulfide, $\mathrm{HS}^{-}$; bisulfite, $\mathrm{HSO}_{3}{ }^{-}$; sulfite, $\mathrm{SO}_{3}{ }^{2-}$ ). Our initial interest in these molecules was stimulated by the role they play in the prebiotic chemistry proposed by Patel et al. (2015), but our calculations are applicable to studies of surficial prebiotic chemistry in general. For discussion of the relevance of the surface environment and its attendant processes to prebiotic chemistry, see, for example, Mulkidjanian et al. (2012), Walker et al. (2012), Forsythe et al. (2015), Mutschler et al. (2015), Rapf and Vaida (2016), Deamer and Damer (2017), He et al. (2017). Our results are not relevant to deep-sea origin-oflife scenarios, such as McCollom and Seewald (2007), Larowe and Regnier (2008), Martin et al. (2008), and Sojo et al. (2016).

We specifically explore the atmosphere as a planetary source for sulfidic anions through dissolution of volcanically outgassed $\mathrm{SO}_{2}$ and $\mathrm{H}_{2} \mathrm{~S}$ in small, shallow aqueous reservoirs like lakes. Prebiotic Earth's atmosphere is thought to have been anoxic and more reducing than modern Earth (Kasting, 2014), and volcanism levels have been hypothesized to have been higher (Richter, 1985). Then the abundance of atmospheric $\mathrm{H}_{2} \mathrm{~S}$ and especially $\mathrm{SO}_{2}$ should have been higher compared to modern-day levels, and aqueous reservoirs in equilibrium with the atmosphere would have dissolved some of these gases in accordance with Henry's law, forming sulfidic anions through subsequent dissociation reactions. We use simple equilibrium chemistry combined with literature photochemical modeling to estimate the concentrations of these sulfidic anions as a function of $\mathrm{pSO}_{2}$ and $\mathrm{pH}_{2} \mathrm{~S}$, and as a function of total sulfur outgassing flux. Elevated levels of atmospheric sulfur can lead to the formation of UVshielding gases and aerosols; consequently, we use radiative transfer calculations to constrain the surface UV radiation environment as a function of total sulfur outgassing flux. UV light is of interest to prebiotic chemists both as a potential stressor for abiogenesis (Sagan, 1973; Cockell, 2000), as a potential eustressor for abiogenesis (Sagan and Khare, 1971; Mulkidjanian et al., 2003; Pascal, 2012; Sarker et al., 2013; Rapf and Vaida, 2016; Xu et al., 2016), and because of evidence that the nucleobases evolved in a UV-rich environment (Rios and Tor, 2013; Beckstead et al., 2016).

We apply our calculations to the case study of the cyanosulfidic prebiotic systems chemistry of Patel et al. (2015). Building on the work of Powner et al. (2009) and Ritson and Sutherland (2012), Patel et al. (2015) proposed a prebiotic reaction network for the synthesis of activated ribonucleotides, short sugars, amino acids and lipid precursors from a limited set of feedstock molecules in aqueous solution under UV irradiation (at $254 \mathrm{~nm}$ ). This reaction network is of interest because of the progress it makes toward the longstanding problem of nucleotide synthesis, because it offers the promise of a common origin for many biomolecules, and because it imposes specific geochemical requirements on its environment, which can be compared against what was available on early Earth to constrain and improve the chemistry's prebiotic plausibility (Higgs and Lehman, 2015; Springsteen, 2015; Šponer et al., 2016). Relevant to our work, the Patel et al. (2015) chemistry requires sulfidic anions to proceed, as both a photoreductant and as a feedstock for a subset of the network's reactions. Patel et al. (2015) proposed impactors as a source for the sulfidic anions; while possible, this scenario imposes an additional, local requirement for this chemistry to function. On the other hand, if the atmosphere could supply adequate sulfidic reductant (and feedstock) on a global basis, it would reduce the requirements for parts (or all) of this reaction network to function, and would make it more compelling as an origins-of-life scenario. We evaluate this scenario. While our paper focuses on the chemistry of Patel et al. (2015) as a case study, our work can be used to evaluate and improve the plausibility of any proposed sulfidic anion-sensitive surficial prebiotic chemistry. Our methods can be adapted to study the prebiotic surficial concentrations of other atmospherically sourced aqueous species.

\section{Background}

\subsection{Plausible prebiotic levels of $\mathrm{H}_{2} \mathrm{~S}$ and $\mathrm{SO}_{2}$}

The abundances of $\mathrm{H}_{2} \mathrm{~S}$ and $\mathrm{SO}_{2}$ in Earth's atmosphere are set by photochemistry and are sensitive to a variety of factors. One of the most important of these factors is the outgassing rate of these compounds from volcanoes into the atmosphere. Absent biogenic sources, atmospheric photochemistry models typically assume abiotic $\mathrm{SO}_{2}$ outgassing rates of $1-3 \times 10^{9} \mathrm{~cm}^{-2} \mathrm{~s}^{-1}$ (Kasting et al., 1989; Zahnle et al., 2006; Hu et al., 2013; Claire et al., 2014), consistent with the measured modern mean volcanogenic $\mathrm{SO}_{2}$ outgassing rate of $1.7-2.4 \times 10^{9} \mathrm{~cm}^{-2} \mathrm{~s}^{-1}$ (Halmer et al., 2002). $\mathrm{H}_{2} \mathrm{~S}$ emission rates are indirectly estimated and much less certain; they range from $3.1 \times 10^{8}$ to $7.7 \times 10^{9} \mathrm{~cm}^{-2} \mathrm{~s}^{-1}$. A common assumption in atmospheric modeling is that $\mathrm{SO}_{2}$ and $\mathrm{H}_{2} \mathrm{~S}$ are outgassed in a 10:1 ratio (e.g., Zahnle et al., 2006; Claire et al., 2014).

Early Earth is often hypothesized to have been characterized by higher levels of volcanic outgassing compared to modern Earth due to presumed higher levels of internal heat and tectonic activity. Models often assume that Archean $\mathrm{SO}_{2}$ outgassing rates were $\sim 3 \times$ modern (Richter, 1985; Kasting et al., 1989; Zahnle et al., 2006). However, Halevy and Head (2014) point out that during the emplacement of major volcanogenic features such as the terrestrial basaltic plains, sulfur outgassing rates as high as $10^{10}$ to $10^{11.5} \mathrm{~cm}^{-2} \mathrm{~s}^{-1}$ are possible, with the upper limit on outgassing rate coming from estimates of sulfur flux during emplacement of the Deccan Traps on Earth (Self et al., 2006).

No firm constraints exist for $\mathrm{SO}_{2}$ and $\mathrm{H}_{2} \mathrm{~S}$ levels on prebiotic Earth. Kasting et al. (1989) modeled a plausible prebiotic atmosphere of 2 bar $\mathrm{CO}_{2}, 0.8$ bar $\mathrm{N}_{2}$ under $0.75 \times$ present-day solar irradiation to account for the effects of the faint young Sun at $3.9 \mathrm{Ga}$. Kasting et al. (1989) assumed that sulfur was outgassed entirely as $\mathrm{SO}_{2}$ at a total sulfur outgassing flux of $\phi_{\mathrm{S}}=3 \times 10^{9} \mathrm{~cm}^{-2} \mathrm{~s}^{-1}$ into an atmosphere overlying an ocean saturated in $\mathrm{SO}_{2}$; this last condition favors accumulation of $\mathrm{SO}_{2}$ in the atmosphere. Claire et al. (2014) modeled an atmosphere of 0.99 bar $\mathrm{N}_{2}$ and 0.01 bar $\mathrm{CO}_{2}$, under irradiation by the $2.5 \mathrm{Ga}$ Sun, with an $\mathrm{SO}_{2}: \mathrm{H}_{2} \mathrm{~S}$ outgassing ratio of $10: 1$, for $\phi_{\mathrm{S}}=1 \times 10^{8}$ to $1 \times 10^{10} \mathrm{~cm}^{-2} \mathrm{~s}^{-1}$. $\mathrm{Hu}$ et al. (2013) modeled an atmosphere consisting of 0.9 bar $\mathrm{CO}_{2}$ and 0.1 bar $\mathrm{N}_{2}$ under irradiation by the modern Sun, with an $\mathrm{SO}_{2}: \mathrm{H}_{2} \mathrm{~S}$ emission ratio of 2 , for $\phi_{\mathrm{S}}=3 \times 10^{9}$ to $1 \times 10^{13} \mathrm{~cm}^{-2} \mathrm{~s}^{-1}$. The $\mathrm{SO}_{2}$ and $\mathrm{H}_{2} \mathrm{~S}$ mixing ratios calculated by these models are shown in Table 1; these mixing ratios may be trivially converted to partial pressures by multiplying against the bulk atmospheric pressure. Note that the Claire et al. (2014) and Kasting et al. (1989) values are surface mixing ratios, while the $\mathrm{Hu}$ et al. (2013) values are 
Table 1. Mixing Ratios of $\mathrm{H}_{2} \mathrm{~S}$ and $\mathrm{SO}_{2}$ For Different Early Earth Models IN THE LiTERATURE AND DifFERENT $\phi_{\mathrm{S}}$

\begin{tabular}{lcc}
\hline Model & $\mathrm{r}_{\mathrm{H}_{2} \mathrm{~S}}$ & $\mathrm{r}_{\mathrm{SO}_{2}}$ \\
\hline Kasting et al. $(1989)^{\mathrm{a}}, \phi_{\mathrm{S}}=3 \times 10^{9} \mathrm{~cm}^{-2} \mathrm{~s}^{-1}$ & $2 \times 10^{-10}$ & $2 \times 10^{-9}$ \\
Claire et al. $(2014)^{\mathrm{a}}, \phi_{\mathrm{S}}=3 \times 10^{9} \mathrm{~cm}^{-2} \mathrm{~s}^{-1}$ & $1 \times 10^{-11}$ & $5 \times 10^{-11}$ \\
Hu et al. $(2013)^{\mathrm{b}}, \phi_{\mathrm{S}}=3 \times 10^{9} \mathrm{~cm}^{-2} \mathrm{~s}^{-1}$ & $4 \times 10^{-10}$ & $3 \times 10^{-10}$ \\
Claire et al. $(2014)^{\mathrm{a}}, \phi_{\mathrm{S}}=1 \times 10^{10} \mathrm{~cm}^{-2} \mathrm{~s}^{-1}$ & $3 \times 10^{-11}$ & $1 \times 10^{-10}$ \\
Hu et al. $(2013)^{\mathrm{b}}, \phi_{\mathrm{S}}=1 \times 10^{10} \mathrm{~cm}^{-2} \mathrm{~s}^{-1}$ & $1 \times 10^{-9}$ & $9 \times 10^{-10}$ \\
\hline
\end{tabular}

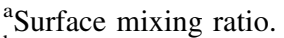

${ }^{\mathrm{b}}$ Column-integrated mixing ratio.

column-integrated mixing ratios. Since $\mathrm{H}_{2} \mathrm{~S}$ and $\mathrm{SO}_{2}$ abundances tend to decrease with altitude due to losses from photochemistry, column-integrated mixing ratios should be somewhat less than the surface mixing ratio. However, since density also decreases with altitude, mixing ratios at lower altitudes are more strongly weighted in the calculation of column-integrated mixing ratios, so the column-integrated mixing ratio tends to be close to the surface mixing ratio.

These models broadly agree that $\mathrm{SO}_{2}$ and $\mathrm{H}_{2} \mathrm{~S}$ levels were low and increase with sulfur emission rate, but their estimates for $r_{\mathrm{SO}_{2}}$ and $r_{\mathrm{H}_{2} \mathrm{~S}}$ disagree with each other by up to a factor of 400 . The $\mathrm{Hu}$ et al. (2013) estimates are typically higher than the other estimates considered. The variation in these abundances demonstrates the sensitivity of $\mathrm{SO}_{2}$ and $\mathrm{H}_{2} \mathrm{~S}$ levels to atmospheric parameters such as composition and deposition velocities. Of these models, we find $\mathrm{Hu}$ et al. (2013) best matches the current fiducial understanding of conditions on early Earth: an atmosphere dominated by $\mathrm{CO}_{2}$ and $\mathrm{N}_{2}$, with volcanic outgassing of both $\mathrm{SO}_{2}$ and $\mathrm{H}_{2} \mathrm{~S}$, with oceans not saturated in $\mathrm{SO}_{2}$ (as compared to possibilities for early Mars; see Halevy et al., 2007). Hu et al. (2013) also has the advantage of calculating atmospheric composition at higher values of sulfur outgassing flux than Kasting et al. (1989) and Claire et al. (2014), encompassing the $1 \times 10^{11.5} \mathrm{~cm}^{-2} \mathrm{~s}^{-1}$ flux which is the upper limit of what Halevy and Head (2014) suggest possible for the emplacement of terrestrial basaltic plains. Hu et al. (2013) model processes including wet and dry deposition, formation of $\mathrm{H}_{2} \mathrm{SO}_{4}$ and $\mathrm{S}_{8}$ aerosol, and photochemistry and thermochemistry, with $>1000$ reactions included in their reaction network. We therefore use $\mathrm{Hu}$ et al. (2013) as a guide when estimating $\mathrm{H}_{2} \mathrm{~S}$ and $\mathrm{SO}_{2}$ levels as a function of sulfur outgassing flux (see Appendix A), with the understanding that further, prebioticEarth-specific modeling is required to constrain this relation with certainty.

\section{Methods}

We consider a gas $Z$ dissolving into a surficial aqueous reservoir ( $\ 1 \mathrm{~m}$ deep), through which the UV light required for prebiotic biomolecule synthesis can penetrate (Ranjan and Sasselov, 2016); our archetypal such environment is a shallow lake. To isolate the effects of atmospheric supply of $Z$, we assume no other source of $Z$ to be present (e.g., no geothermal source at the lake bottom). Henry's law states that the concentration of $Z,[Z]$, in aqueous solution at the air/water interface is proportional to the partial pressure of the gas at that interface. We assume the aqueous reservoir to be well mixed and equilibrated throughout, so that the concentration of $[Z]$ is uniform throughout the reservoir at the surficial value. If the reservoir is not well mixed, then the dissolved gas concentration will vary deeper into the reservoir. Under our assumption of no non-atmospheric source of $Z,[Z]$ would decrease with depth for a poorly mixed aqueous reservoir.

This method of calculating $[Z]$ is predicated on the assumption that the aqueous body is in equilibrium with the atmosphere, that is, that the solution is saturated in $Z$ and the sink and source of $Z$ is outgassing and deposition from the atmosphere. This assumption is valid when there are no other sinks to drive the system away from equilibrium. We discuss the veracity of this assumption in Section 5.2. In brief, this assumption is valid for shallow, well-mixed lakes that are not very acidic or hot, but not valid for deep, acidic, or hot waters. For these scenarios, our calculations provide upper bounds on $[Z]$.

In aqueous solution, $\mathrm{H}_{2} \mathrm{~S}$ undergoes the dissociation reactions

$$
\begin{gathered}
\mathrm{H}_{2} \mathrm{~S} \rightarrow \mathrm{HS}^{-}+\mathrm{H}^{+}, \mathrm{p} K_{\mathrm{a}_{\mathrm{H}_{2} \mathrm{~S}, 1}}=7.05 \\
\mathrm{HS}^{-} \rightarrow \mathrm{S}^{2-}+\mathrm{H}^{+}, \mathrm{p} K_{\mathrm{a}_{\mathrm{H}_{2} \mathrm{~S}, 2}}=19
\end{gathered}
$$

where the $\mathrm{p} K_{\mathrm{a}}$ values are taken from Lide (2009) and can be related to the corresponding equilibrium constants by $K_{\mathrm{a}_{X}}=10^{-\mathrm{p} K_{\mathrm{a}_{X}}}$. Similarly, $\mathrm{SO}_{2}$ undergoes the reactions

$$
\begin{gathered}
\mathrm{SO}_{2}+\mathrm{H}_{2} \mathrm{O} \rightarrow \mathrm{HSO}_{3}^{-}+\mathrm{H}^{+}, \mathrm{p} K_{\mathrm{asO}_{2}, 1}=1.86 \\
\mathrm{HSO}_{3}^{-} \rightarrow \mathrm{SO}_{3}{ }^{2-}+\mathrm{H}^{+}, \mathrm{p}_{\mathrm{asO}_{2}, 2}=7.2 \\
\mathrm{HSO}_{3}^{-}+\mathrm{SO}_{2} \rightarrow \mathrm{HS}_{2} \mathrm{O}_{5}^{-}, \mathrm{p}_{\mathrm{asO}_{2,3}}=1.5
\end{gathered}
$$

where the $\mathrm{p} K_{\mathrm{a}}$ values are from Neta and Huie (1985).

To compute the abundances of these different sulfurbearing compounds as a function of [Z], we must make assumptions as to the background chemistry of the aqueous reservoir they are dissolved in, especially its $\mathrm{pH}$. If the reservoir is completely unbuffered (e.g., pure water), its $\mathrm{pH}$ (and hence the speciation of S-bearing compounds) will be completely determined by $[Z]$. At the other extreme, if the reservoir is completely buffered, its $\mathrm{pH}$ will be independent of [Z]. Natural waters typically lie in between these two extremes; they are often buffered by mineral or atmospheric 
interactions toward a certain $\mathrm{pH}^{1}$, but with enough atmospheric supply their buffers can be overwhelmed. We explore these bracketing cases below, with the understanding that the true speciation behavior in nature was most likely somewhere in between.

\subsection{Calculating dissolved gas concentration}

We use Henry's law, coupled with the well-mixed reservoir assumption, to calculate the concentration of molecules dissolved from the atmosphere. Henry's law states that for a species $Z$,

$$
[Z]=H_{Z} f_{Z}
$$

where $H_{Z}$ is the gas-specific Henry's law constant and $f_{Z}$ is the fugacity of the gas. Over the range of temperatures and pressures relevant to surficial prebiotic chemistry, the gases in our study are ideal, and consequently $f_{Z}=p_{Z}$, the partial pressure of $Z$. We make this simplifying assumption throughout our study.

At $T_{0}=298.15 \mathrm{~K}$, the Henry's law constants for $\mathrm{H}_{2} \mathrm{~S}$ and $\mathrm{SO}_{2}$ dissolving in pure water are $H_{\mathrm{H}_{2} \mathrm{~S}}=0.101 \mathrm{M} / \mathrm{bar}$ and $H_{\mathrm{SO}_{2}}=1.34 \mathrm{M} / \mathrm{bar}$, respectively. Increasing salinity tends to decrease $H_{G}$, a process known as salting out. Similarly, increasing temperature also tends to decrease $H_{C}$. Our overall results are insensitive to variations in temperature of $25 \mathrm{~K}$ from $T_{0}$ and $0 \leq[\mathrm{NaCl}] \leq 1 M$; see Appendix $\mathrm{C}$ and Appendix D.1. For simplicity, we therefore neglect the temperature- and salinity-dependence of Henry's law.

\subsection{Unbuffered solution}

Consider an unbuffered solution with dissolved $Z$, whose properties are determined entirely by the reactions $Z$ and its products undergo. From the definition of equilibrium constant, we can use the $\mathrm{H}_{2} \mathrm{~S}$ and $\mathrm{SO}_{2}$ speciation reactions to write

$$
\begin{aligned}
& \frac{a_{\mathrm{HS}}-a_{\mathrm{H}^{+}}}{a_{\mathrm{H}_{2} \mathrm{~S}}}=K_{\mathrm{a}_{\mathrm{H}_{2} \mathrm{~S}, 1}} \\
& \frac{a_{\mathrm{S}^{2}}-a_{\mathrm{H}^{+}}}{a_{\mathrm{HS}^{-}}}=K_{\mathrm{a}_{\mathrm{H}_{2} \mathrm{~S}, 2}}
\end{aligned}
$$

and

$$
\begin{aligned}
& \frac{a_{\mathrm{HSO}_{3}}-a_{\mathrm{H}^{+}}}{a_{\mathrm{SO}_{2}}}=K_{\mathrm{aSO}_{2}, 1} \\
& \frac{a_{\mathrm{SO}_{3}^{2}}-a_{\mathrm{H}^{+}}}{a_{\mathrm{HSO}_{3}^{-}}}=K_{\mathrm{aSO}_{2}, 2} \\
& \frac{a_{\mathrm{HS}_{2} \mathrm{O}_{5}^{-}}}{a_{\mathrm{SO}_{2}} a_{\mathrm{HSO}_{3}^{-}}}=K_{\mathrm{aSO}_{2,3}}
\end{aligned}
$$

${ }^{1}$ For example, the oceans on modern Earth are buffered to a $\mathrm{pH}$ of 8.1-8.2 due primarily to carbonate buffering (Hall-Spencer $e t$ al., 2008; Zeebe and Wolf-Gladrow, 2009); estimates of ancient ocean $\mathrm{pH}$ vary but often invoke slightly lower $\mathrm{pH}$ due to posited higher $\mathrm{CO}_{2}$ levels early in Earth's history (see, e.g., Morse and Mackenzie, 1998; Amend and McCollom, 2009; Halevy and Bachan, 2017, and sources therein). Smaller bodies, like lakes, can have an even wider range of $\mathrm{pH}$ values due to local conditions; lakes on modern Earth can have $\mathrm{pH}<1$ (e.g., Kawah Ijen crater lake; Löhr et al., 2005) and pH > 11 (e.g., Lake Natron; Grant and Jones, 2000).
Where $a_{C}$ is the activity of species $C . a_{C}$ is related to the concentration of $C,[C]$, by $a_{C}=\gamma_{C}[C]$, where $\gamma_{C}$ is the activity coefficient (Misra, 2012). The use of activities instead of concentrations accounts for ion-ion and ion- $\mathrm{H}_{2} \mathrm{O}$ interactions. $\gamma=1$ for a solution with an ionic strength of $I=0$. For ionic strengths of $0-0.1 \mathrm{M}$, we calculate the activity coefficients for each species as a function of solution ionic strength using Extended Debye-Huckel theory (Debye and Huckel, 1923). The activity coefficients in this formalism are calculated by

$$
\log \left(\gamma_{C}\right)=-A z_{C}^{2} \frac{I^{0.5}}{1+B \alpha_{C} I^{0.5}}
$$

Here, $A$ and $B$ are constants that depend on the temperature, density, and dielectric constant of the solvent; we use $A=0.5085 M^{-1 / 2}$ and $B=0.3281 M^{-1 / 2} \AA^{-1}$, corresponding to $25^{\circ} \mathrm{C}$ water (Misra, 2012) (our results are robust to this assumption; see Appendix D). $z_{C}$ is the charge of species $C . \alpha_{C}$ is an ion-specific parameter with values related to the hydration radius of the aqueous species; we took our $\alpha_{C}$ values from Misra (2012). We were unable to locate a value of $\alpha_{C}$ for $\mathrm{HS}_{2} \mathrm{O}_{5}{ }^{-}$and consequently take $\gamma_{\mathrm{HS}_{2} \mathrm{O}_{5}{ }^{-}}=1$ throughout. $I$ is the ionic strength of the solution, defined as

$$
I=0.5\left(\Sigma_{C}[C] z_{C}^{2}\right)
$$

We can combine these equations with the equation for water dissociation:

$$
\begin{gathered}
\mathrm{H}_{2} \mathrm{O} \rightarrow \mathrm{OH}^{-}+\mathrm{H}^{+}, \mathrm{p} K_{\mathrm{w}}=14 \\
\left(a_{\mathrm{H}^{+}}\right)\left(a_{\mathrm{OH}^{-}}\right)=K_{\mathrm{w}}
\end{gathered}
$$

and the requirement for charge conservation:

$$
\Sigma_{C} z_{C}[C]=0
$$

With [Z] specified by Henry's law and our assumption of a well-mixed reservoir, this system is fully determined, and we can numerically solve it to determine the concentration of each of the species above as a function of $p_{Z}$ and $I$. A wide range of ionic strengths are possible for natural waters; modern freshwater systems like rivers have typical ionic strengths of order $1 \times 10^{-3} M$ (Lerman et al., 1995), whereas modern terrestrial oceans have an ionic strength of $0.7 \mathrm{M}^{2}$. The concentrations of divalent cations, especially $\mathrm{Mg}^{2+}$ and $\mathrm{Ca}^{2+}$, in early oceans have been suggested to be near $10 \mathrm{mM}$ (Deamer and Dworkin, 2005). A more fundamental constraint comes from vesicle formation, which is known to be inhibited at high salt concentrations and hence ionic strengths: Maurer and Nguyen (2016) report that lipid vesicle formation is impeded in solutions with $I>0.1 \mathrm{M}$. These considerations motivate our focus on low-ionic-strength waters, with $I \leq 0.1 M^{3}$.

\footnotetext{
${ }^{2} \mathrm{http} / / /$ www.aqion.de/site/69, accessed 29 November 2016.

${ }^{3} \mathrm{~A}$ further practical challenge with extending our calculations to higher ionic strengths is that the parameters required to compute the activity coefficients at high ionic strengths (e.g., via the Truesdell and Jones, 1974 formalism) are not available for many of the species we consider.
} 

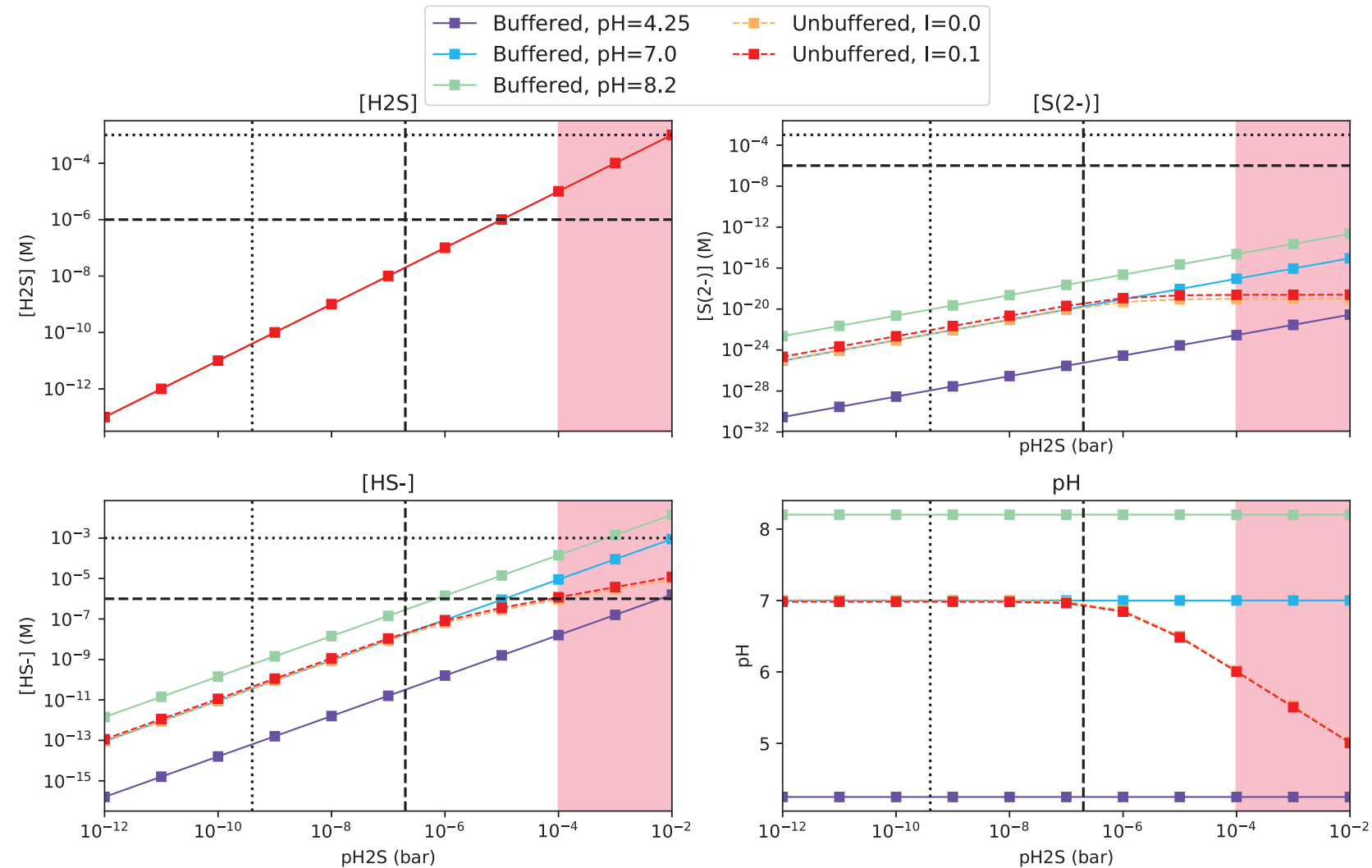

FIG. 1. Concentrations of sulfur-bearing compounds and $\mathrm{pH}$ as a function of $\mathrm{pH}_{2} \mathrm{~S}$ for a well-mixed aqueous reservoir. $\left[\mathrm{H}_{2} \mathrm{~S}\right]$ is calculated from Henry's law; the concentrations of $\mathrm{HS}^{-}$and $\mathrm{S}^{2-}$ are calculated from equilibrium chemistry for (1) solutions buffered to various $\mathrm{pH}$ values and (2) unbuffered solutions with varying ionic strengths. The vertical dotted line demarcates the expected $\mathrm{pH}_{2} \mathrm{~S}$ for an abiotic Earth with a weakly reducing $\mathrm{CO}_{2}-\mathrm{N}_{2}$ atmosphere with modern levels of sulfur outgassing, from $\mathrm{Hu}$ et al. (2013). The vertical dashed line demarcates the expected $\mathrm{pH}_{2} \mathrm{~S}$ for the same model but with outgassing levels of sulfur corresponding to the upper limit of the estimate for the emplacement of the terrestrial flood basalts. In the red shaded area, $\mathrm{pH}_{2} \mathrm{~S}$ is so high it blocks UV light from the planet surface, meaning UV-dependent prebiotic pathways, e.g., those of Patel et al. (2015), cannot function (Ranjan and Sasselov, 2017). The red curve largely overplots the orange, demonstrating the minimal impact of ionic strength on the calculation for $I \leq 0.1$. The horizontal dashed and dotted lines demarcate micromolar and millimolar concentrations, respectively. The cyanosulfidic chemistry of Patel et al. (2015) has been demonstrated at millimolar S-bearing photoreductant concentrations, and at least high micromolar levels of these compounds are thought to be required for high-yield prebiotic chemistry.

We calculate the speciation of sulfur-bearing species from dissolved $\mathrm{H}_{2} \mathrm{~S}$ and $\mathrm{SO}_{2}$ for $I=0$ and $I=0.1 M$; the results are shown in Figs. 1 and 2. $I=0$ is the lowest possible ionic strength, and $I=0.1 M$ corresponds to the limit from lipid vesicle formation.

\subsection{Buffered solution}

Consider now an aqueous reservoir that is buffered to a given $\mathrm{pH}$. For example, the $\mathrm{pH}$ of the modern oceans is buffered by calcium carbonate to a global mean value of 8.1-8.2 (Hall-Spencer et al., 2008). Then, we know $\left[\mathrm{H}^{+}\right]$, and can hence calculate the speciation of dissolved $\mathrm{H}_{2} \mathrm{~S}$ and $\mathrm{SO}_{2}$ from the equilibrium constant Eqs. 7-8 and 9-11 individually. Our results are insensitive to ionic strength for $I \leq 0.1 M$ (see Figs. 1 and 2, and Appendix B), and $I \leq 0.1 M$ is required for vesicle formation and other prebiotic chemistry (Maurer and Nguyen, 2016; Deamer and Damer, 2017), motivating us to take $I=0$ for simplicity.

With Henry's law and our assumption of a well-mixed reservoir, we can readily calculate the concentration of the above species as a function of $\mathrm{pH}_{2} \mathrm{~S}$ or $\mathrm{pSO}_{2}$ and $\mathrm{pH}$. The results of this calculation are presented in Figs. 1 and 2 for three representative $\mathrm{pH}$ values. We selected $\mathrm{pH}=8.2$, corresponding to modern ocean; $\mathrm{pH}=7$, corresponding to the nearneutral phosphate-buffered conditions in which Patel et al. (2015) conducted their experiments; and $\mathrm{pH}=4.25$, corresponding to raindrops in a $\mathrm{pCO}_{2} \sim 0.1$ bar atmosphere (Halevy et al., 2007). Such high $\mathrm{CO}_{2}$ levels are hypothesized for young Earth in order to power a greenhouse effect large enough to maintain clement surface conditions (Kasting, 1993).

The code used to implement these calculations is available for validation and extension at https://github.com/sukritranjan/ RanjanToddSutherlandSasselov2017.git.

\section{Results}

\section{1. $\mathrm{H}_{2} \mathrm{~S}$ versus $\mathrm{SO}_{2}$}

Figure 1 shows the speciation of sulfur-bearing compounds from dissolved $\mathrm{H}_{2} \mathrm{~S}$ for an unbuffered reservoir, and reservoirs buffered to various $\mathrm{pH}$ values. Over the range of ionic strengths considered, $\mathrm{HS}^{-}$is the dominant anion, and $\mathrm{S}^{2-}$ 


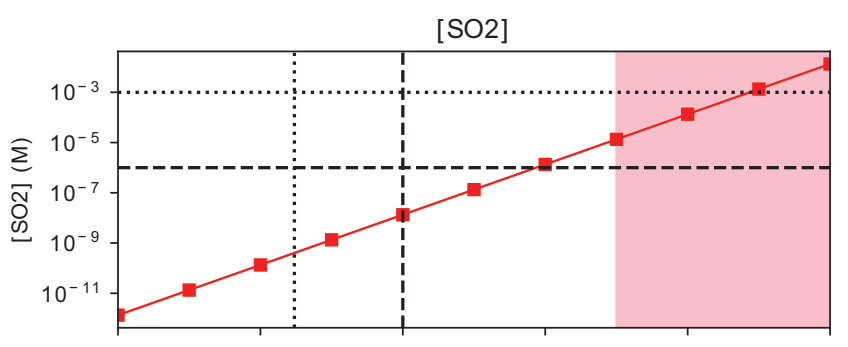

$[\mathrm{SO} 2]$
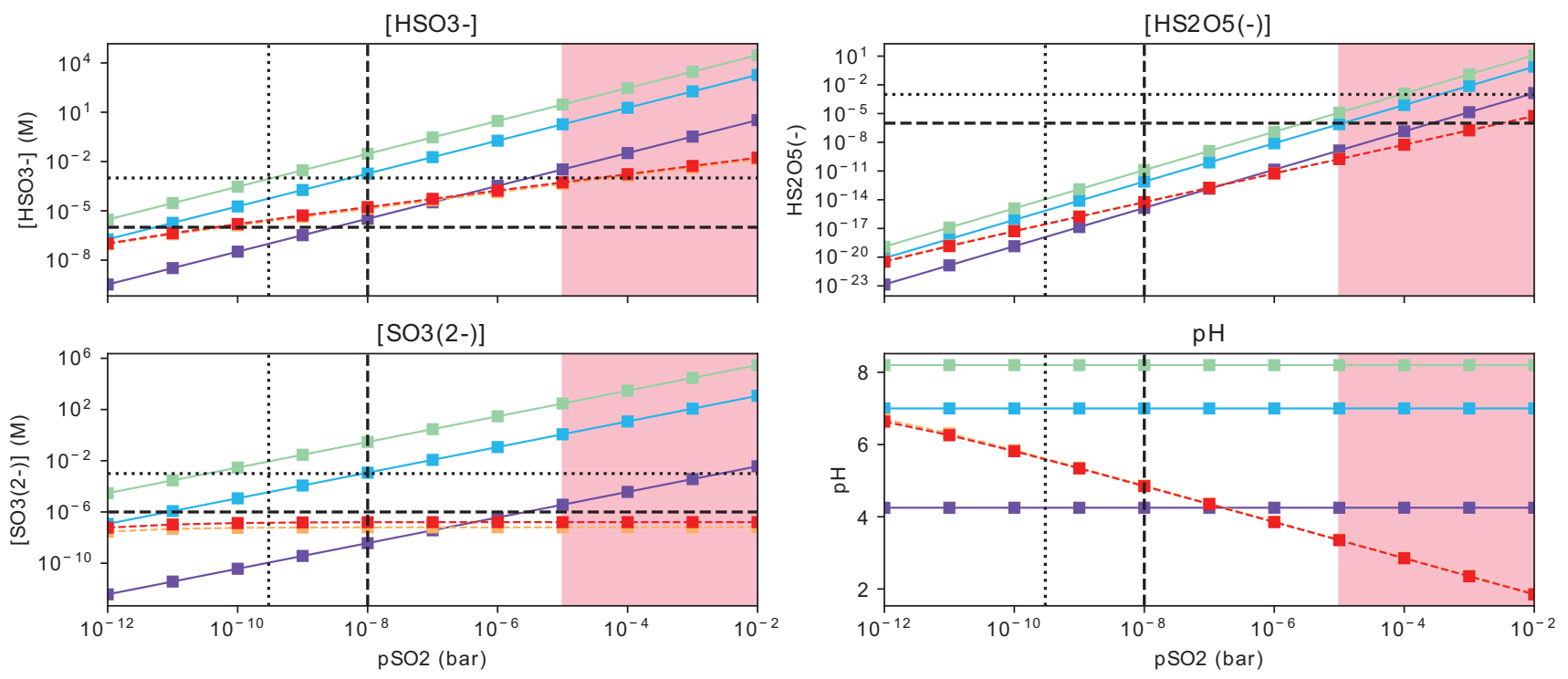

FIG. 2. Concentrations of sulfur-bearing compounds and $\mathrm{pH}$ as a function of $\mathrm{pSO}_{2}$ for a well-mixed aqueous reservoir. $\left[\mathrm{SO}_{2}\right]$ is calculated from Henry's law; the concentrations of $\mathrm{HSO}_{3}{ }^{-}, \mathrm{SO}_{3}{ }^{2-}$, and $\mathrm{HS}_{2} \mathrm{O}_{5}{ }^{-}$are calculated from equilibrium chemistry for (1) solutions buffered to various $\mathrm{pH}$ values and (2) unbuffered solutions with varying ionic strengths. The vertical dotted line demarcates the expected $\mathrm{pSO}_{2}$ for an abiotic Earth with a weakly reducing $\mathrm{CO}_{2}-\mathrm{N}_{2}$ atmosphere with modern levels of sulfur outgassing, from $\mathrm{Hu}$ et al. (2013). The vertical dashed line demarcates the expected $\mathrm{pSO}_{2}$ for the same model, but with outgassing levels of sulfur corresponding to the upper limit of the estimate for the emplacement of the terrestrial flood basalts. In the red shaded area, $\mathrm{pSO}_{2}$ is so high it blocks UV light from the planet surface, meaning UVdependent prebiotic pathways, e.g., those of Patel et al. (2015), cannot function (Ranjan and Sasselov, 2017). The red curve largely overplots the orange, demonstrating the minimal impact of ionic strength on the calculation for $I \leq 0.1$. The horizontal dashed and dotted lines demarcate micromolar and millimolar concentrations, respectively. The cyanosulfidic chemistry of Patel et al. (2015) has been demonstrated at millimolar S-bearing photoreductant concentrations, and at least high micromolar levels of these compounds are thought to be required for high-yield prebiotic chemistry.

is present at negligible concentrations. As $\mathrm{pH}_{2} \mathrm{~S}$ increases, the $\mathrm{pH}$ of the unbuffered reservoir drops, but slowly. This is expected, since $\mathrm{H}_{2} \mathrm{~S}$ is a weak acid.

Figure 2 shows the speciation of sulfur-bearing compounds from dissolved $\mathrm{SO}_{2}$ for an unbuffered reservoir, and reservoirs buffered to various $\mathrm{pH}$ values. Because of the lack of $\mathrm{O}_{2}$ in this anoxic era, the first dissociation of $\mathrm{SO}_{2}$ forms sulfite, rather than sulfate. $\mathrm{HSO}_{3}{ }^{-}$and $\mathrm{SO}_{3}{ }^{2-}$ are present at comparable levels; $\mathrm{HS}_{2} \mathrm{O}_{5}{ }^{-}$is negligible. As $\mathrm{pSO}_{2}$ increases, the $\mathrm{pH}$ of the unbuffered reservoir falls off rapidly; this is expected since hydrated $\mathrm{SO}_{2}$ is a strong acid.

$\mathrm{SO}_{2}$ is an order of magnitude more soluble than $\mathrm{H}_{2} \mathrm{~S}$, and its first dissociation is much more strongly favored $\left(\mathrm{p} K_{\mathrm{asO}_{2}, 1}=1.86\right.$ vs. $\left.\mathrm{p} K_{\mathrm{a}_{\mathrm{H}_{2} \mathrm{~S}, 1}}=7.05\right)$. Consequently, far higher concentrations of sulfidic anions can be sustained for a given $\mathrm{pSO}_{2}$ than for the same $\mathrm{pH}_{2} \mathrm{~S}$ (see Figs. 1 and 2). Maintaining micromolar concentrations of $\mathrm{HS}^{-}$requires $\mathrm{pH}_{2} \mathrm{~S} \geq 1 \times 10^{-6}$ bar at $\mathrm{pH}=8.2$ (modern ocean), and $\mathrm{pH}_{2} \mathrm{~S} \geq 1 \times 10^{-5}$ bar for more neutral $\mathrm{pH}$ values. Maintaining micromolar concentrations of $\mathrm{S}^{2-}$ is impossible over plausible ranges of $\mathrm{pH}$ and sulfur outgassing flux $\left(\mathrm{p} K_{\mathrm{a}_{\mathrm{H}_{2} \mathrm{~S}, 2}}=19\right)$. The concentration of sulfidic anions could be increased by going to higher $\mathrm{pH}$ and salinity. However, the reactions of, for example, Patel et al. (2015) have not been demonstrated to proceed under such conditions.

By contrast, dissolved $\mathrm{SO}_{2}$ gives rise to comparatively high concentrations of sulfidic anions due to higher solubility and a more favorable first ionization. Micromolar concentrations of $\mathrm{HSO}_{3}^{-}$are possible for $\mathrm{pSO}_{2}>1 \times 10^{-11}$ bar for all but very acidic solutions; micromolar concentrations of $\mathrm{SO}_{3}{ }^{2-}$ are possible for solutions buffered to $\mathrm{pH}$ $\geq 7$ over the same range. Millimolar levels of $\mathrm{HSO}_{3}{ }^{-}$and $\mathrm{SO}_{3}{ }^{2-}$ are possible for solutions buffered to $\mathrm{pH} \geq 8.2$ for $\mathrm{pSO}_{2} \gtrsim 10^{-10}$ bar, and for $\mathrm{pH} \geq 7$ solutions for $\mathrm{pSO}_{2} \gtrsim 10^{-8}$ bar. $\mathrm{pSO}_{2} \geq 3 \times 10^{-10}$ bar is expected for outgassing rates corresponding to the steady state on early Earth according to the model of $\mathrm{Hu}$ et al. $(2013)\left(\phi_{\mathrm{S}}=3 \times 10^{9} \mathrm{~cm}^{-2} \mathrm{~s}^{-1}\right)$. During transient epochs of intense volcanism such as the emplacement of basaltic plains, emission rates might have risen as high as $\phi_{\mathrm{S}}=10^{11.5} \mathrm{~cm}^{-2} \mathrm{~s}^{-1}$ (Self et al., 2006; Halevy and Head, 2014), corresponding to $\mathrm{pSO}_{2}=1 \times 10^{-8}$ bar. We note 


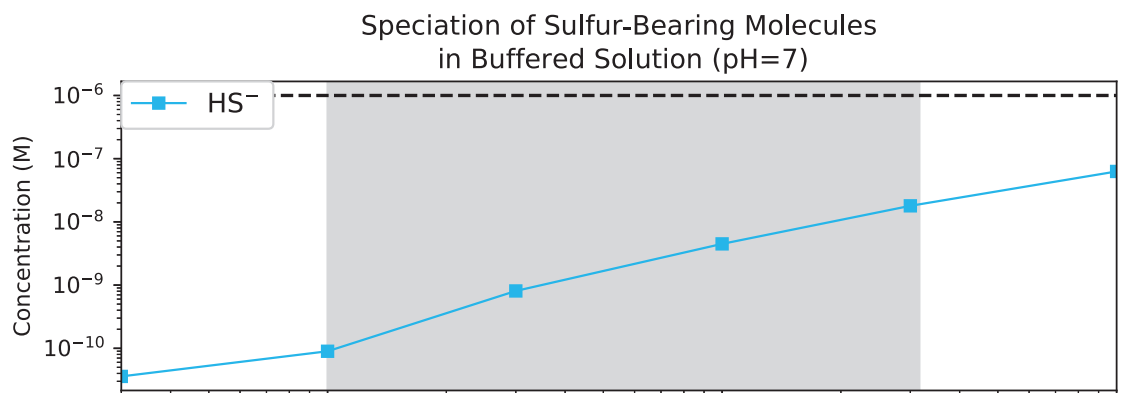

FIG. 3. Speciation of sulfur-bearing molecules in an aqueous reservoir buffered to $\mathrm{pH}=7$ as a function of total sulfur emission flux $\phi_{\mathrm{S}}$. The range of $\phi_{\mathrm{S}}$ highlighted by Halevy and Head (2014) for emplacement of basaltic plains on Earth is shaded in gray. Horizontal dashed and dotted lines demarcate micromolar and millimolar concentrations, respectively.

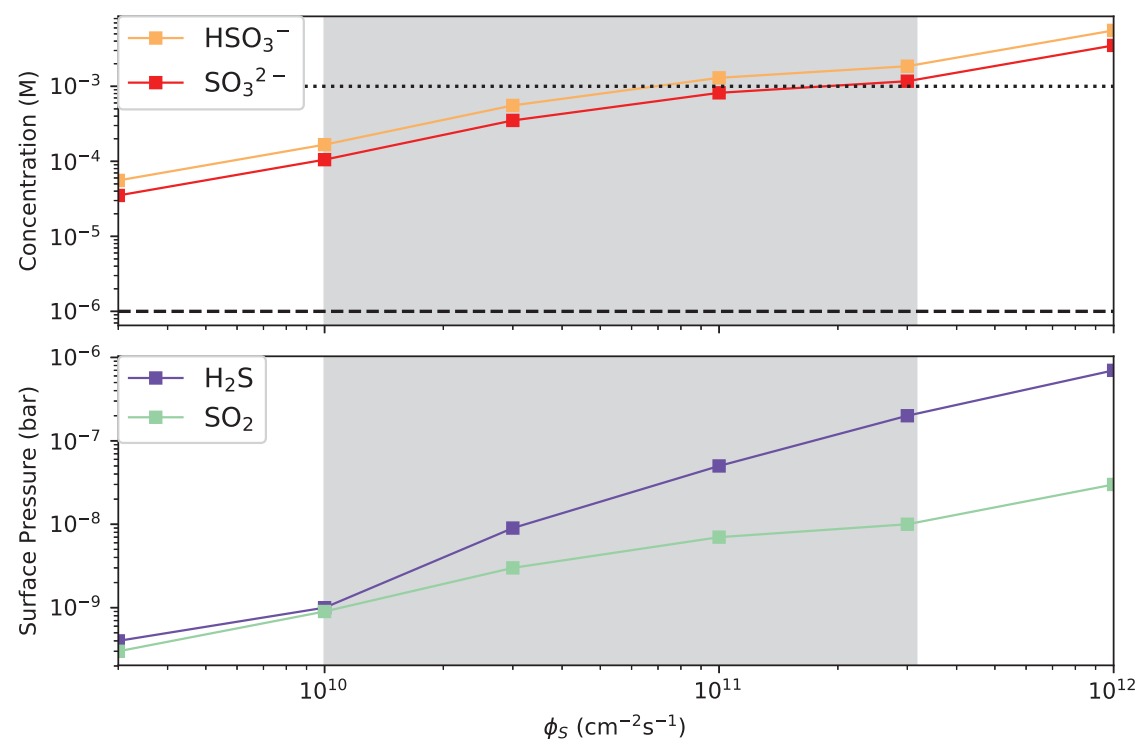

that estimates based on $\mathrm{Hu}$ et al. (2013) are for columnintegrated abundances, and the surface abundances were likely modestly larger. Hence, it seems likely that the atmosphere could have supplied micromolar levels of $\mathrm{SO}_{2}$-derived anions for prebiotic chemistry, and perhaps even millimolar concentrations if the solution were buffered to slightly alkaline $\mathrm{pH}$ (e.g., $\mathrm{pH}$ comparable to the modern ocean).

\section{2. $\mathrm{H}_{2} \mathrm{~S}$ and $\mathrm{SO}_{2}$}

In Section 4.1 we evaluated the prospects for buildup of sulfur-bearing anions from dissolved atmospheric $\mathrm{H}_{2} \mathrm{~S}$ and $\mathrm{SO}_{2}$ in isolation. However, $\mathrm{H}_{2} \mathrm{~S}$ and $\mathrm{SO}_{2}$ are injected simultaneously into the atmosphere by volcanism and would have been present at the same time. Figure 3 presents the speciation of sulfur-bearing molecules from dissolved atmospheric $\mathrm{H}_{2} \mathrm{~S}$ and $\mathrm{SO}_{2}$ in a solution buffered to $\mathrm{pH}=7$ as a function of total sulfur outgassing rate, $\phi_{\mathrm{S}}$. This $\mathrm{pH}$ corresponds approximately to the phosphate-buffered conditions in which the chemistry of Patel et al. (2015) proceeded ${ }^{4}$. If the solution were buffered to higher $\mathrm{pH}$, sulfidic anion concentrations would be higher due to a more favorable first dissociation, and vice versa.

As before, we connected the $\mathrm{H}_{2} \mathrm{~S}$ and $\mathrm{SO}_{2}$ abundances to $\phi_{\mathrm{S}}$ by the high- $\mathrm{CO}_{2}$ model calculations of $\mathrm{Hu}$ et al. (2013).

\footnotetext{
${ }^{4}$ It is thought that these chemistries should proceed over a broad range of $\mathrm{pH}$. However, they will proceed best for $\mathrm{pH} \lesssim 9.2$ (so that $\mathrm{HCN}$ tends to remain protonated) and $\mathrm{pH} \gtrsim 7$ (so that the sulfidic anions tend to remain deprotonated)
}

We took the surface mixing ratio of these gases to equal the column-integrated mixing ratio, which may slightly underestimate the surface mixing ratio of these gases. $\phi_{\mathrm{S}}=1-3 \times 10^{9} \mathrm{~cm}^{-2} \mathrm{~s}^{-1}$ for modern Earth and $\phi_{\mathrm{S}}=10^{10}$ to $10^{11.5} \mathrm{~cm}^{-2} \mathrm{~s}^{-1}$ have been suggested on a transient $(1-10$ year) basis for major volcanic episodes like the emplacement of basaltic plains on Earth (Self et al., 2006; Halevy and Head, 2014). As discussed in Section 4.1, $\mathrm{SO}_{2}$-derived anions can build to micromolar levels at modern outgassing rates and can build to millimolar levels during volcanic episodes like the emplacement of basaltic plains, while $\mathrm{H}_{2} \mathrm{~S}$ derived anions cannot, absent highly alkaline conditions.

\subsection{Coupling to the UV surface environment}

$\mathrm{H}_{2} \mathrm{~S}, \mathrm{SO}_{2}$, and their photochemical aerosol by-products $\left(\mathrm{S}_{8}, \mathrm{H}_{2} \mathrm{SO}_{4}\right)$ are robust UV shields, and at elevated levels their presence can dramatically reduce surface UV radiation (Hu et al., 2013; Ranjan and Sasselov, 2017). This effect could be good for origin-of-life scenarios which do not require UV light, since UV light can photolytically destroy newly formed biomolecules (e.g., Sagan, 1973). On the other hand, it could be bad for UV-dependent prebiotic chemistry, which depends on UV light to power their syntheses (e.g., Ritson and Sutherland, 2012; Patel et al., 2015; Xu et al., 2016). In the latter case, it begs the question whether the elevated levels of $\mathrm{SO}_{2}$ and $\mathrm{H}_{2} \mathrm{~S}$ that could supply the sulfidic anions required for cyanosulfidic chemistry might also quench the UV radiation also required by these pathways.

To explore this question, we calculated the attenuation of incoming $3.9 \mathrm{Ga}$ solar radiation (calculated from the models 


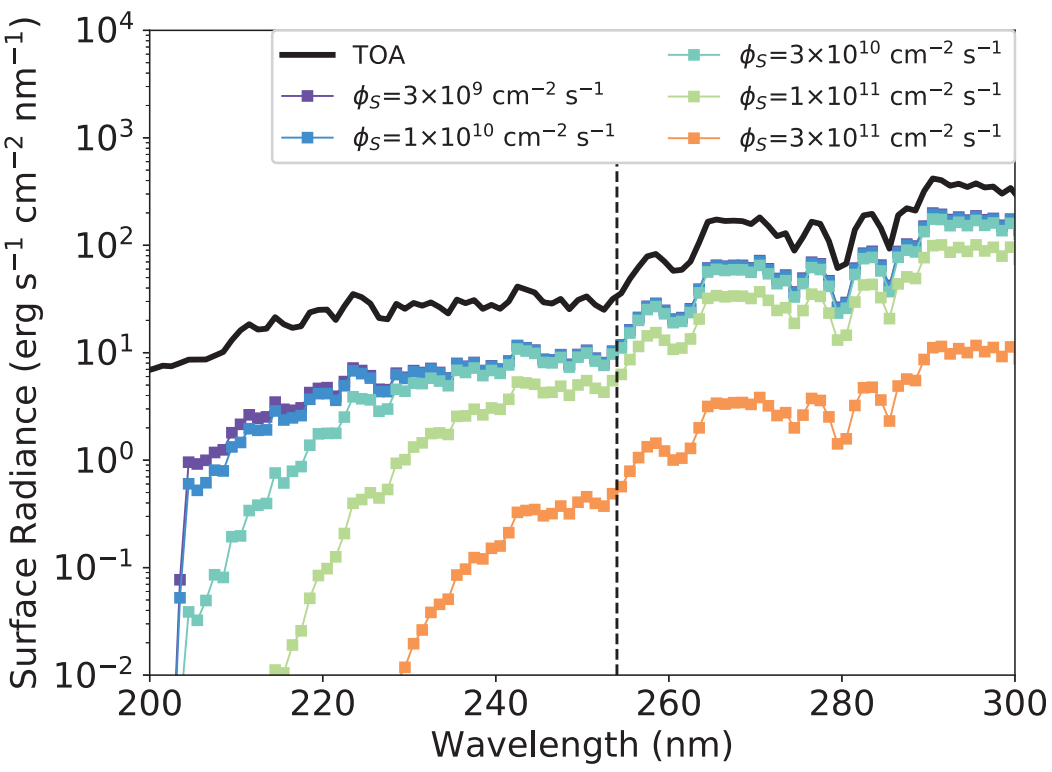

FIG. 4. UV surface radiance for early Earth as a function of $\phi_{\mathrm{S}}$, using the models of $\mathrm{Hu}$ et al. (2013). The black solid line indicates the top-of-atmosphere (TOA) flux, i.e., the irradiation incident at the top of the atmosphere from the young Sun. The vertical dashed line demarcates $254 \mathrm{~nm}$, the wavelength at which the low-pressure mercury lamps commonly used in prebiotic chemistry experiments emit. of Claire et al., 2012) by a $\mathrm{CO}_{2}-\mathrm{N}_{2}-\mathrm{SO}_{2}-\mathrm{H}_{2} \mathrm{~S}$ atmosphere, using a two-stream radiative transfer model (Ranjan and Sasselov, 2017; Ranjan et al., 2017). We set the solar zenith angle to $48.2^{\circ}$, corresponding to the insolation-weighted mean value (Cronin, 2014), and the albedo to 0.2 , a representative value for rocky planets consistent with past modeling ${ }^{5}$ (Segura et al., 2003; Rugheimer et al., 2015). We once again used the work of $\mathrm{Hu}$ et al. (2013) to connect $\mathrm{H}_{2} \mathrm{~S}$ and $\mathrm{SO}_{2}$ abundances to $\phi_{\mathrm{S}}$, and for consistency we assumed inventories of $\mathrm{CO}_{2}$ and $\mathrm{N}_{2}$ matching those assumed by $\mathrm{Hu}$ et al. (2013) (their high- $\mathrm{CO}_{2}$ case). Our radiative transfer calculations are insensitive to the atmospheric $T / P$ profile, because atmospheric emission is negligible at UV wavelengths and our UV cross-sections vary minimally as a function of temperature (Ranjan et al., 2017); consequently, we assume a simple exponential profile to the vertical number density of the atmosphere. We also used the work of $\mathrm{Hu}$ et al. (2013) to estimate the total $\mathrm{S}_{8}$ and $\mathrm{H}_{2} \mathrm{SO}_{4}$ aerosol loading in the atmosphere for each $\phi_{\mathrm{S}}$, and calculated aerosol optical parameters using the same size distributions and complex indices of refraction as they did. Lacking detailed atmospheric profiles of the aerosol abundance as a function of altitude, we assumed the aerosols were distributed exponentially, with a scale height equal to the bulk atmospheric scale height (i.e., well mixed). In practice, sulfur aerosols tend to form photolytically at higher altitudes, meaning our approach places more aerosol at low altitude and less aerosol at high altitude. Since the radiative impact of aerosol absorption is amplified lower in the atmosphere due to enhanced scattering, this means our treatment should slightly overestimate UV attenuation due to aerosols. Similarly, Hu et al. (2013) assume an aerosol size distribution with surface area mean diameter $D_{\mathrm{S}}=0.1 \mu \mathrm{m}$, at the lower end of the plausible $D_{\mathrm{S}}=0.1-1 \mu \mathrm{m}$ range, which maximizes the possible radiative impact of the sulfur aerosols. Consequently, our results should be interpreted as a lower bound on the true UV fluence.

\footnotetext{
${ }^{5}$ Our results are insensitive to the precise choice of albedo or solar zenith angle.
}

Figure 4 presents the UV fluence available on the surface of the prebiotic Earth as a function of $\phi_{\mathrm{S}}$ under these assumptions. For $\phi_{\mathrm{S}} \leq 1 \times 10^{11} \mathrm{~cm}^{-2} \mathrm{~s}^{-1}$, UV radiation remains abundant on the planet surface. Millimolar levels of $\mathrm{SO}_{3}{ }^{2-}$ and $\mathrm{HSO}_{3}{ }^{-}$are available in aqueous reservoirs buffered to $\mathrm{pH}$ $\geq 7$ for $\phi_{\mathrm{S}}=1 \times 10^{11} \mathrm{~cm}^{-2} \mathrm{~s}^{-1}$. Consequently, volcanism could supply prebiotically relevant levels of $\mathrm{SO}_{3}{ }^{2-}$ and $\mathrm{HSO}_{3}{ }^{-}$ without blocking off the UV radiation required by UVdependent prebiotic pathways for sulfur emission fluxes up to $\phi_{\mathrm{S}} \leq 1 \times 10^{11} \mathrm{~cm}^{-2} \mathrm{~s}^{-1}$ (near the upper edge of what is considered plausible for major terrestrial volcanic episodes). On the other hand, for $\phi_{\mathrm{S}} \geq 3 \times 10^{11} \mathrm{~cm}^{-2} \mathrm{~s}^{-1}$, atmospheric sulfurbearing gases and aerosols, especially the UV-absorbing $\mathrm{S}_{8}$, suppress surface UV radiation by an order of magnitude or more; this paucity of UV radiation may pose a challenge for UV-dependent prebiotic chemistry but could create a very clement surface environment for UV-independent prebiotic chemistries. If one accepts the idea that the nucleobases show evidence of UV selection pressure (Crespo-Hernández et al., 2004; Serrano-Andres and Merchan, 2009; Rios and Tor, 2013; Beckstead et al., 2016; Pollum et al., 2016), this suggests the biogenic nucleobases evolved in an epoch with $\phi_{\mathrm{S}} \leq$ $1 \times 10^{11} \mathrm{~cm}^{-2} \mathrm{~s}^{-1}$.

\section{Discussion}

\subsection{Sulfidic anion concentrations in surficial waters on early Earth}

We have shown that terrestrial volcanism could have globally supplied the sulfidic anions $\mathrm{SO}_{3}{ }^{2-}$ and $\mathrm{HSO}_{3}{ }^{-}$, derived from the dissolution of $\mathrm{SO}_{2}$ into aqueous solution, to shallow surficial aqueous reservoirs on early Earth. These compounds would have been available at micromolar levels for volcanic outgassing rates comparable to the modern day. During episodes of high volcanism, such as those responsible for emplacement of basaltic plains $\left(\phi_{\mathrm{S}} \approx 1 \times 10^{11} \mathrm{~cm}^{-2} \mathrm{~s}^{-1}\right)$, these compounds could have built up to the millimolar levels in shallow aqueous reservoirs buffered to $\mathrm{pH} \geq 7$. On the other hand, due to its lower solubility and unfavorable first dissociation, sulfidic anions derived from dissolving atmospheric $\mathrm{H}_{2} \mathrm{~S}$ 
can only be supplied at low concentrations (sub-micromolar) across the plausible range of $\mathrm{pH}_{2} \mathrm{~S}$ and $\mathrm{pH}^{6}$. Therefore, other mechanisms must be invoked for supply of such anions, if required by a proposed prebiotic chemical pathway.

We conducted our calculations assuming a temperature of $T=25^{\circ} \mathrm{C}$. We investigate the sensitivity of our results to temperatures ranging from $T=0^{\circ} \mathrm{C}$ to $50^{\circ} \mathrm{C}$ in Appendix D, including temperature effects on both the reaction rate and the Henry's law coefficient. While $\mathrm{H}_{2} \mathrm{~S}$-derived anion concentrations are not significantly affected by temperature variations in this range, $\mathrm{SO}_{2}$-derived anion concentrations are. This is because $H_{\mathrm{SO}_{2}}$ decreases with temperature and $\mathrm{p} K_{\mathrm{aSO}_{2,1}}$ increases with temperature ${ }^{7}$; both effects favor decreased concentrations of $\mathrm{HSO}_{3}{ }^{-}$and its derivatives with increasing temperature, assuming a not highly acidic $(\mathrm{pH}>2.5)$ solution. We find that while our overall conclusions are unchanged, concentrations of the $\mathrm{SO}_{2}$-derived anions $\mathrm{HSO}_{3}{ }^{-}$and $\mathrm{SO}_{3}{ }^{2-}$ are an order of magnitude higher for $T \approx 0^{\circ} \mathrm{C}$ relative to $T=25^{\circ} \mathrm{C}$, and an order of magnitude lower for $T \approx 50^{\circ} \mathrm{C}$, assuming a near-neutral reservoir. Consequently, cooler waters are more favorable environments for prebiotic chemistry which invokes $\mathrm{HSO}_{3}{ }^{-}$or $\mathrm{SO}_{3}{ }^{2-}$.

Sulfur-bearing gases and aerosols, in particular $\mathrm{S}_{8}$, are strong UV absorbers, and if present at high enough levels could suppress UV-sensitive prebiotic chemistry. For $\phi_{\mathrm{S}} \leq$ $1 \times 10^{11} \mathrm{~cm}^{-2} \mathrm{~s}^{-1}$, corresponding to most of the plausible range of sulfur emission fluxes on early Earth, surface UV fluxes $(200-300 \mathrm{~nm}$ ) are not significantly attenuated by atmospheric absorbers, meaning that in the steady state and for most volcanic eruptions, abundant UV light should have reached Earth's surface to power UV-dependent prebiotic chemistry. However, for the very largest volcanic eruptions, corresponding to the uppermost end of the plausible range of sulfur outgassing fluxes during terrestrial basaltic flood plain emplacement $\left(\phi_{\mathrm{S}}=3 \times 10^{11} \mathrm{~cm}^{-2} \mathrm{~s}^{-1}\right)$, surface UV fluence (200-300 nm) may be reduced by an order of magnitude or more. Hence, the very largest volcanic events ${ }^{8}$ might create an especially clement surficial environment for UVindependent prebiotic chemistry.

These results were derived using the high- $\mathrm{CO}_{2}$ model of $\mathrm{Hu}$ et al. (2013), which, while plausible, assumes more $\mathrm{CO}_{2}$ and less $\mathrm{N}_{2}$ than other models of prebiotic Earth (e.g., Rugheimer et al., 2015) and is hence comparatively oxidizing. We explored the sensitivity of our results to this assumption via the $\mathrm{N}_{2}$-rich model of $\mathrm{Hu}$ et al. (2013). This model assumes 1 bar of $\mathrm{N}_{2}$ and negligible $\mathrm{CO}_{2}$ and is hence an unrealistic

\footnotetext{
${ }^{6}$ Our results are relevant to shallow, aqueous bodies of water, like lakes. By contrast, in the ocean, volcanoes vent directly into the water, and the turnover time can be long. Consequently, one could envision significant buildup of $\mathrm{H}_{2} \mathrm{~S}$ near deep-ocean volcanoes. This scenario is beyond the scope of this work but may be worthy of consideration for $\mathrm{HS}^{-}$-dependent chemistry.

${ }^{7}$ The exothermic first dissociation of $\mathrm{SO}_{2}$ is disfavored at higher temperatures.

${ }^{8}$ However, even in this case there may be a window in which prebiotic chemistry experiences both elevated $\mathrm{SO}_{2}$ levels and plenty of UV light, since aerosol formation is not instantaneous. Detailed photochemical modeling is required to determine the timescale of aerosol formation after a large volcanic eruption on early Earth; absent such modeling, we note that on modern Earth, formation of sulfate aerosols from volcanic eruptions occurs on a timescale of weeks (Robock, 2000); we may speculate a similar timescale for aerosol formation on early Earth.
}

approximation to early Earth, because an appreciable $\mathrm{CO}_{2}$ inventory is expected due to climate constraints (Kasting, 1993; Wordsworth and Pierrehumbert, 2013) and due to volcanic outgassing of $\mathrm{CO}_{2}$. Hence, this model serves as an extreme bounding case. Assuming this model, we find that $\mathrm{H}_{2} \mathrm{~S}$ and $\mathrm{SO}_{2}$ levels are lower than for the high- $\mathrm{CO}_{2}$ case. $\mathrm{SO}_{2^{-}}$ derived anions remain available at micromolar levels over the plausible range of $\phi_{\mathrm{S}}$ but in order to build to millimolar levels require the assumption of reservoirs buffered to slightly alkaline $\mathrm{pH}$ (e.g., $\mathrm{pH} \sim 8.2$, modern ocean). $\mathrm{HS}^{-}$levels are even lower than in the $\mathrm{CO}_{2}$-rich case. UV fluences are lower than in the $\mathrm{CO}_{2}$-rich case, due to elevated levels of $\mathrm{S}_{8}$ formation in this more reducing atmosphere; surface UV fluence (200$300 \mathrm{~nm}$ ) is suppressed by an order of magnitude or more for $\phi_{\mathrm{S}} \geq 1 \times 10^{11} \mathrm{~cm}^{-2} \mathrm{~s}^{-1}$. Overall, this boundary case suggests that our finding that the atmosphere can supply prebiotically relevant levels of $\mathrm{SO}_{2}$-derived anions but not $\mathrm{H}_{2} \mathrm{~S}$-derived anions in conjunction with UV light remains true across a broad range of $\mathrm{CO}_{2}$ and $\mathrm{N}_{2}$ abundances, though both sulfidic anion abundances and UV are lower for more reducing, $\mathrm{N}_{2}$-rich atmospheres. However, a detailed exploration of the $\mathrm{pCO}_{2}-\mathrm{pN}_{2}$ parameter space with photochemical models is required to be certain of these findings.

\subsection{Impact of other sinks}

Our analysis is predicated on the assumption that $[Z]$ is set by Henry equilibrium, that is, that the aqueous reservoir is saturated in $\mathrm{H}_{2} \mathrm{~S}$ and $\mathrm{SO}_{2}$. This assumes no major sinks other than outgassing to the atmosphere. In this section, we examine the sensitivity of our results to this assumption. Microbial sinks (e.g., Halevy, 2013) are not relevant since we are concerned with prebiotic Earth; neither are oxic sinks, since the surface of early Earth was anoxic (Kasting and Walker, 1981; Kasting, 1987; Farquhar et al., 2001; Pavlov and Kasting, 2002; Li et al., 2013). However, reactions with metal cations to produce insoluble precipitates and redox reactions could have been relevant; we explore these sinks.

5.2.1. Precipitation reactions with metal cations. We explored the possibility that reactions of $\mathrm{S}$ anions with metal cations might lead to formation of insoluble precipitates, which would act as a sink on S-anion concentrations. Such cations might have been delivered to aqueous reservoirs via weathering of rocks and minerals.

Under standard conditions, $\mathrm{Fe}^{2+}$ and $\mathrm{Cu}^{2+}$ react with $\mathrm{H}_{2} \mathrm{~S}(\mathrm{aq})$ to generate insoluble precipitates, like $\mathrm{CuS}$ and $\mathrm{FeS}_{2}$ (Rickard and Luther, 2007; Rumble, 2017). Interaction of copper sulfides with cyanide solution can liberate $\mathrm{HS}^{-}$ (Coderre and Dixon, 1999), as invoked by Patel et al. (2015). In general, high- $\mathrm{Cu} / \mathrm{Fe}$ waters (e.g., due to interaction with ores) will be even more $\mathrm{HS}^{-}$-poor than we have modeled, with the caveat that specific local environmental factors (like the presence of aqueous cyanide) can prevent sulfide depletion due to precipitation. This reinforces our conclusion that $\mathrm{HS}^{-}$concentrations are unlikely to have reached prebiotically relevant levels on early Earth, absent unique local factors. For example, the aqueous cyanide required as a feedstock in the pathways of Patel et al. (2015) would also permit elevated $\mathrm{HS}^{-}$levels.

$\mathrm{Ca}^{2+}$, produced by mineral weathering, reacts with sulfite to produce insoluble $\mathrm{CaSO}_{3}$. Studying the $\mathrm{Ca}^{2+}-\mathrm{SO}^{2-}$ system 
requires considering the effects of carbonate $\left(\mathrm{CO}_{3}{ }^{2-}\right)$ as well, because $\mathrm{Ca}^{2+}$ forms precipitate with this anion as well, and because high levels of carbonate are expected in natural waters on early Earth due to elevated levels of atmospheric $\mathrm{CO}_{2}$ required to solve the faint young Sun paradox (Kasting, 1987). While precisely modeling this geochemical system requires use of a geochemical model capable of accounting for all reactions involving sulfites and carbonates and their kinetics, we can get a first-order estimate of the impact of $\mathrm{Ca}^{2+}$, as follows. Assuming parameters from $\mathrm{Hu}$ et al. (2013), the flux of carbonates into solution due to deposition and speciation of atmospheric $\mathrm{CO}_{2}$ is $r_{\mathrm{CO}_{2}} n_{\mathrm{atm}} v_{\text {dep }, \mathrm{CO}_{2}}=2 \times 10^{15} \mathrm{~cm}^{-2} \mathrm{~s}^{-1}$ on the $\mathrm{CO}_{2}$-rich early Earth, which exceeds the mean flux of $\mathrm{Ca}$ due to mineral weathering $\left(1-5 \times 10^{10} \mathrm{~cm}^{-2} \mathrm{~s}^{-1}\right.$; Watmough and Aherne, 2008; Taylor et al., 2012) by 5 orders of magnitude; thus, it is reasonable to assume the solution is saturated in $\mathrm{CO}_{2}$ with abundance dictated by Henry's law of $\left(3.3 \times 10^{-2} \mathrm{M} /\right.$ bar $)(0.9$ bar $)=0.03 M$ (Sander, 2015). Then, $\left[\mathrm{CO}_{3}{ }^{2-}\right]=(0.03$ $M)\left(10^{7-6.35}\right)\left(10^{7-10.33}\right)=6 \times 10^{-5} M$ at neutral $\mathrm{pH}$ (dissociation constants $K_{\mathrm{a}_{2}, 1}=6.35$ and $K_{\mathrm{aCO}_{2,1}}=10.33$ from Rumble [2017] $\left.{ }^{9}\right)$. Since $\mathrm{CaCO}_{3}\left(K_{\mathrm{sp}}=3.36 \times 10^{-9} M^{2}\right.$, Rumble, 2017) is 2 orders of magnitude less soluble than $\mathrm{CaSO}_{3}\left(K_{\mathrm{sp}}=3.1 \times 10^{-7}\right.$ $M^{2}$, Rumble, 2017) and the sulfite flux is much less than the carbonate flux, we can assume that $\left[\mathrm{Ca}^{2+}\right]$ is dictated to first order by equilibrium with carbonate mineral, that is, $\left[\mathrm{Ca}^{2+}\right]=$ $3.36 \times 10^{-9} M^{2} / 6 \times 10^{-5} M=6 \times 10^{-5} M$. At this $\left[\mathrm{Ca}^{2+}\right]$, $\mathrm{CaSO}_{3}{ }^{2-}(\mathrm{s})$ will begin to form at $\left[\mathrm{SO}_{3}{ }^{2-}\right]=3.1 \times 10^{-7} \mathrm{M}^{2}$ / $6 \times 10^{-5} M=5 \times 10^{-3} M$. The $\left[\mathrm{SO}_{3}{ }^{2-}\right]$ we calculate does not exceed this threshold value across the plausible range of sulfur outgassing fluxes in our calculation, meaning the solution is unsaturated in $\mathrm{CaSO}_{3}$ and precipitate does not form. Were $\mathrm{pCO}_{2}$ lower, for example, $\mathrm{pCO}_{2}=0.2 \mathrm{bar}^{10}, \mathrm{CaSO}_{3}$ precipitate formation begins at $\left[\mathrm{SO}_{3}{ }^{2-}\right]=1 \times 10^{-3} \mathrm{M}$. However, if $\mathrm{pH}$ were low, the carbonate solubility would exceed sulfite solubility, and sulfite precipitates would form (Halevy et al., 2007); hence, at low $\mathrm{pH}$, sulfite and bisulfite concentrations will be below the values we calculate. Overall, our results are unaffected by $\mathrm{CaSO}_{3}$ precipitation across most of parameter space, but $\mathrm{CaSO}_{3}$ precipitation might be a significant sink on aqueous sulfite levels for acid solutions and/or for very low atmospheric $\mathrm{CO}_{2}$-levels; calculations with a more thorough geochemical model (e.g., PHREEQC, Parkhurst and Appelo, 2013) are required to constrain $\mathrm{S}$-anion concentrations in this regime.

5.2.2. Redox reactions. We explored the possibility that redox reactions (disproportionation, comproportionation) might have acted as sinks to $\mathrm{S}$-anion concentrations in shallow aqueous reservoirs on prebiotic Earth, or might otherwise affect the distribution of sulfidic anions. We identified the following reactions that are spontaneous near standard conditions (Siu and Jia, 1999; Halevy, 2013):

$$
4 \mathrm{SO}_{3}{ }^{2-}+\mathrm{H}^{+} \rightarrow 2 \mathrm{SO}_{4}{ }^{2-}+\mathrm{S}_{2} \mathrm{O}_{3}{ }^{2-}+\mathrm{H}_{2} \mathrm{O}
$$

\footnotetext{
${ }^{9}$ Using $\mathrm{p} K_{\mathrm{a}}$ values for $\mathrm{CO}_{2}$ dissociation from modern seawater, e.g., Zeebe and Wolf-Gladrow (2009), results in much higher carbonate levels, much lower Ca levels, and a much higher threshold for $\mathrm{CaSO}_{3}$ saturation, so this treatment is conservative.

${ }^{10}$ Corresponding to the lower limit suggested by Kasting (1987) from climate considerations.
}

$$
2 \mathrm{HS}^{-}+4 \mathrm{HSO}_{3}{ }^{-} \rightarrow 3 \mathrm{~S}_{2} \mathrm{O}_{3}{ }^{2-}+3 \mathrm{H}_{2} \mathrm{O}
$$

The kinetics of Reaction 17 are not well characterized near standard temperature and are an active topic of research (Mirzoyan and Halevy, 2014; Amshoff et al., 2016). Meyer et al. (1982) report sulfite and bisulfite are stable on timescales $\geq 1$ year in anoxic conditions, while Guekezian et al. (1997) report decay of sulfite in days at $\mathrm{pH} \geq 12.8$. Halevy (2013) propose that rate coefficients in the range $k_{17}=\exp \left(\frac{-50 \mathrm{~kJ} \mathrm{~mol}^{-1}}{R T}\right)-\exp \left(\frac{-40 \mathrm{~kJ} \mathrm{~mol}^{-1}}{R T}\right) \mathrm{s}^{-1}$ are plausible; at $293 \mathrm{~K}$, this corresponds to $1 \times 10^{-9}$ to $7 \times 10^{-8}$ $\mathrm{s}^{-1}$, which correspond to timescales of $0.5-30$ years. The kinetics of Reaction 18 have been determined as a function of temperature at $\mathrm{pH}=9$ and $I=0.2 M$ by Siu and Jia (1999). At $293 \mathrm{~K}$, the rate coefficient is $k_{18}=4 \times 10^{3} \mathrm{M}^{-2} \mathrm{~s}^{-1}$. At the $\mathrm{S}$-anion concentrations relevant to our work ${ }^{11}$, the timescale of this reaction is $\gtrsim 1$ year. For comparison, putative prebiotic chemistry in laboratory studies often occurs on timescales of hours to days (Patel et al., 2015; $\mathrm{Xu}$ et al., in press, e.g.).

We test the effects of redox reactions on S-anion concentrations by carrying out a dynamical equilibrium calculation for a shallow lake buffered to $\mathrm{pH}=7$, with source the atmosphere and sink these redox reactions. Following the treatment of Halevy (2013), the equilibrium equations can be written:

$$
\begin{aligned}
r_{\mathrm{H}_{2} \mathrm{~S}} n_{\mathrm{atm}} v_{\mathrm{dep}, \mathrm{H}_{2} \mathrm{~S}} A_{\text {catch }}= & \left(\frac{2}{3} k_{18}\left[\mathrm{HS}^{-}\right]\left[\mathrm{HSO}_{3}{ }^{-}\right]^{2}\right) A_{\text {lake }} d_{\text {lake }} \\
r_{\mathrm{SO}_{2}} n_{\text {atm }} v_{\text {dep }, \mathrm{SO}_{2}} A_{\text {catch }}= & \left(\frac{4}{3} k_{18}\left[\mathrm{HS}^{-}\right]\left[\mathrm{HSO}_{3}{ }^{-}\right]^{2}\right. \\
& \left.+k_{17}[\mathrm{~S}(\mathrm{IV})]\right) A_{\text {lake }} d_{\text {lake }}
\end{aligned}
$$

For consistency with $\mathrm{Hu}$ et al. (2013), we adopt $v_{\text {dep, } \mathrm{H}_{2} \mathrm{~S}}=0.015 \mathrm{~cm} \mathrm{~s}^{-1}, v_{\mathrm{dep}, \mathrm{SO}_{2}}=1 \mathrm{~cm} \mathrm{~s}^{-1}, T=288 \mathrm{~K}$, and $n_{\mathrm{atm}}=\frac{1 \mathrm{bar}}{k T}=2.4 \times 10^{19} \mathrm{~cm}^{-3}$. Since we are concerned with shallow, well-mixed lakes, we take the lake depth $d_{\text {lake }}=10^{2}$ cm. $A_{\text {catch }}$ is the catchment area of the lake, and $A_{\text {lake }}$ is the surface area of the lake; we conservatively adopt $A_{\text {catch }}=A_{\text {lake, }}$, which likely underestimates sulfur supply since the catchment area is often larger than the lake area. [S(IV)] refers to the total concentration of S(IV) atoms in solution, and is calculated as $[\mathrm{S}(\mathrm{IV})]=\left[\mathrm{SO}_{2}\right]+\left[\mathrm{HSO}_{3}{ }^{-}\right]+\left[\mathrm{SO}_{3}{ }^{2-}\right]+2\left[\mathrm{HS}_{2} \mathrm{O}_{5}{ }^{-}\right] \approx$ $\left[\mathrm{SO}_{2}(\mathrm{aq})\right]+\left[\mathrm{HSO}_{3}{ }^{-}\right]+\left[\mathrm{SO}_{3}{ }^{2-}\right]^{12}$. Since we have specified $\mathrm{pH}=7$ and know the relevant $\mathrm{p} K_{\mathrm{a}}$ values, we can calculate $\left[\mathrm{HSO}_{3}{ }^{-}\right]$from $[\mathrm{S}(\mathrm{IV})]$ and vice versa. With $r_{\mathrm{H}_{2} \mathrm{~S}}$ and $r_{\mathrm{SO}_{2}}$ specified from $\mathrm{Hu}$ et al. (2013), we have a system of two equations in two variables that we can solve. Figure 5 shows the resultant S-anion concentrations as a function of $\phi_{\mathrm{S}}$.

The dynamic calculation is very sensitive to the uncertainty in $k_{17}$, with sulfite and bisulfite concentrations varying by 2 orders of magnitude and hydrosulfide concentrations

\footnotetext{
${ }^{11}\left[\mathrm{HS}^{-}\right] \lesssim 10^{-8} M,\left[\mathrm{HSO}_{3}^{-}\right] \lesssim 10^{-3} M$.

${ }^{12}\left[\mathrm{HS}_{2} \mathrm{O}_{5}^{-}\right]$is negligible for dilute $\left[\mathrm{SO}_{2}\right]$.
} 
FIG. 5. Speciation of sulfur-bearing molecules in a shallow lake buffered to $\mathrm{pH}=7$ as a function of total sulfur emission flux $\phi_{\mathrm{S}}$, using a dynamic calculation with source atmospheric deposition and sink redox reactions. The range of $\phi_{\mathrm{S}}$ highlighted by Halevy and Head (2014) for emplacement of basaltic plains on Earth is shaded in gray. Horizontal dashed and dotted lines demarcate micromolar and millimolar concentrations, respectively. $\left[\mathrm{HS}^{-}\right]$would not be able to achieve the high concentrations calculated here for the slow disproportionation (low $k_{17}$ ) case due to solubility constraints.
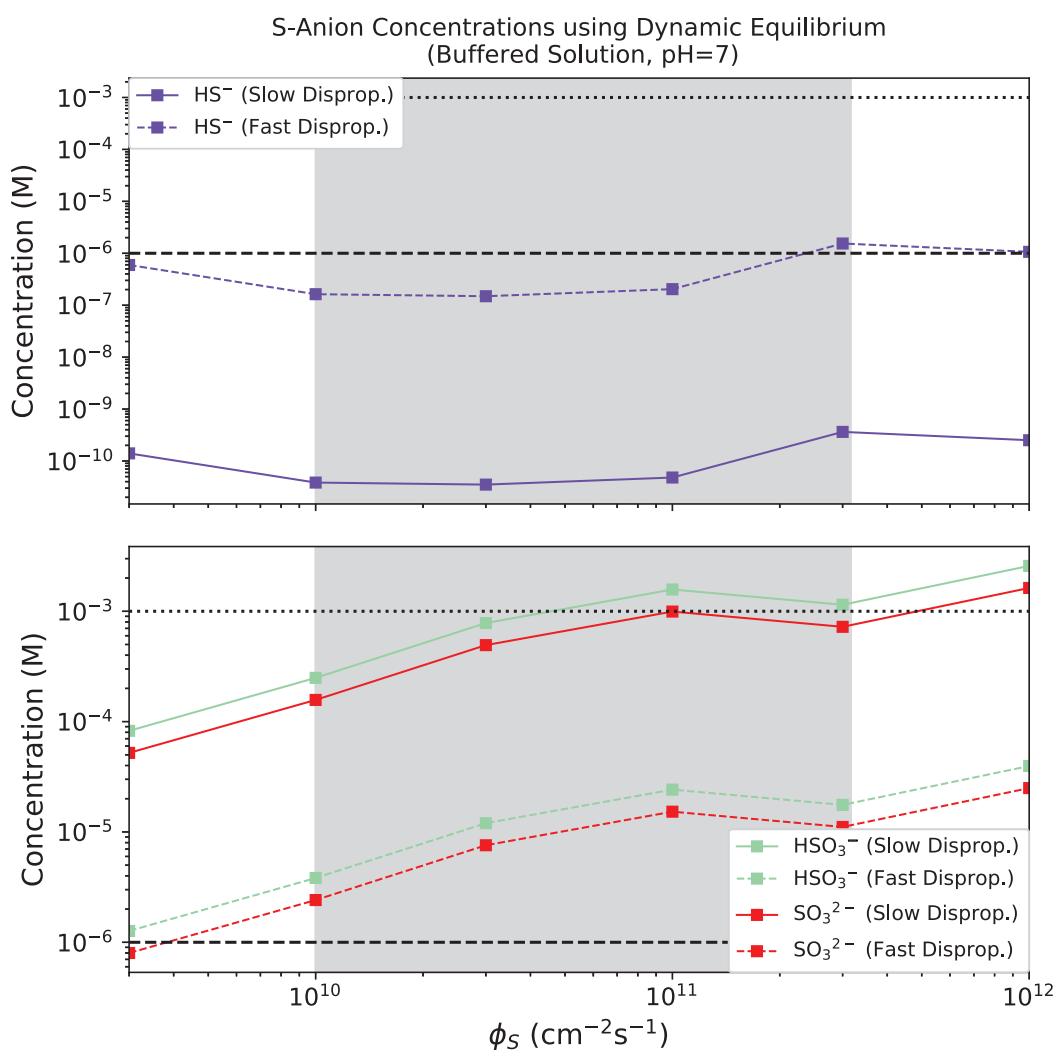

varying by 4 across the range of $k_{17}$ suggested by Halevy (2013). However, even with this uncertainty it is clear that prebiotically relevant levels $(\geq 1 \mu M)$ of $\mathrm{SO}_{2}$-derived anions are available across the range of plausible sulfur outgassing fluxes, with concentrations $\sim 1-10 \mu M$ if sulfite disproportionation is fast and $\sim 100-1000 \mu M$ if sulfite disproportionation is slow. Note depending on $k_{17}$, it is possible for $\left[\mathrm{HS}^{-}\right]$in the dynamic calculation to exceed the value calculated from solubility constraints; in reality, in well-mixed solution $\mathrm{H}_{2} \mathrm{~S}$ would de-gas when it reached the solubility limit, voiding Eq. 19. In these cases, $\left[\mathrm{HS}^{-}\right]$is lower than the value calculated from the dynamic method, modestly increasing sulfite and bisulfite concentrations since Reaction 18 is slower. S-anion concentrations increase as $d_{\text {lake }}$ and $T$ decrease, and are ultimately limited by gas solubility. Overall, our finding that prebiotically relevant levels of $\mathrm{SO}_{2-}$ derived anions were available in shallow well-mixed lakes on early Earth is robust to the effect of redox reactions, but it is possible for the precise concentrations to be lower than from our equilibrium calculation depending on the depth and temperature of the lake, and especially on the rate of sulfite disproportionation $k_{17}$. Constraining $k_{17}$ is key to improved modeling of abiotic sulfur chemistry.

\subsection{Case study: Implications for cyanosulfidic systems chemistry of Patel et al. (2015)}

The cyanosulfidic prebiotic chemistry of Patel et al. (2015) requires cyanide and sulfur-bearing anions, both as feedstocks and as sources of hydrated electrons through UVdriven photoionization. Patel et al. (2015) used $\mathrm{HS}^{-}$as their sulfidic anion, and propose impact-derived sources of metal sulfides (both from the impactor and from subsequent metallogenesis) and evaporatively concentrated iron sulfides as a source for $\mathrm{HS}^{-}$. This postulated mechanism requires specific, local environmental conditions to function. By contrast, simple exposure of a non-acidic lake to the atmosphere anywhere on the planet would supply $\mathrm{HSO}_{3}{ }^{-}$and $\mathrm{SO}_{3}{ }^{2-}$ at prebiotically relevant levels to either supplement the photochemical reducing capacity of $\mathrm{HS}^{-}$or function as sole sources of hydrated electrons in the Patel et al. (2015) chemistry. Indeed, recent work by the same group suggests that $\mathrm{HSO}_{3}{ }^{-}$and $\mathrm{SO}_{3}{ }^{2-}$ can replace $\mathrm{HS}^{-}$as the source of hydrated electrons upon UV irradiation, and thus drive those parts of the reaction network that do not rely on $\mathrm{HS}^{-}$as a feedstocks (Xu et al., in press). Reducing or eliminating the dependence of the Patel et al. (2015) chemistry on $\mathrm{HS}^{-}$in favor of $\mathrm{HSO}_{3}{ }^{-}$or $\mathrm{SO}_{3}{ }^{2-}$ increases the robustness of this chemistry, because no special local circumstances need to be invoked. This illustrates how geochemistry can inform improvements of the plausibility of prebiotic pathways.

Indeed, volcanism can be a source of more than sulfidic anions. Volcanism can also be a source of phosphates through partial hydrolysis of volcanically outgassed polyphosphates (Yamagata et al., 1991), and a supplementary source of $\mathrm{HCN}$ through photochemical reprocessing of volcanically outgassed reducing species like $\mathrm{CH}_{4}$ (Zahnle, $1986)^{13}$. Volcanism could thereby supply or supplement many of the C-, H-, O-, N-, P-, and S-containing feedstock molecules and photoreductants required by the Patel et al. (2015) chemistry. The UV light also required by the Patel et al. (2015) chemistry would be available at Earth's surface for all but the largest volcanic episodes $\left(\phi_{\mathrm{S}} \geq 3 \times 10^{11} \mathrm{~cm}^{-2}\right.$ $\mathrm{s}^{-1}$ ). Hence, epochs of moderately high volcanism may have

\footnotetext{
${ }^{13}$ Though some concentration mechanism would be required to achieve prebiotically relevant levels of $\mathrm{HCN}$ via this pathway.
} 
been uniquely conducive to cyanosulfidic prebiotic chemistry like that of Patel et al. (2015), especially if they can be adapted to work with $\mathrm{HSO}_{3}{ }^{-}$or $\mathrm{SO}_{3}{ }^{2-}$ instead of $\mathrm{HS}^{-}$.

We considered alternate planetary sources for $\mathrm{HS}^{-}$for the Patel et al. (2015) chemistry. We explored whether shallow hydrothermal systems, such as hot springs, might provide prebiotically relevant levels of $\mathrm{HS}^{-}$. These sources are highsulfur systems on modern Earth, and, if shallow, prebiotic chemistry in them might retain access to UV light while accessing high concentrations of sulfidic anions. Surveys of modern hydrothermal systems reveal examples of surficial systems that exhibit micromolar or even millimolar concentrations of $\mathrm{HS}^{-}$(Xu et al., 1998; Vick et al., 2010; Kaasalainen and Stefánsson, 2011). However, high concentrations of $\mathrm{HS}^{-}$appear to only be achieved in hot systems ${ }^{14}$ ( $T>60^{\circ} \mathrm{C}$, and typically higher). Similarly, studies of geothermal waters in Yellowstone National Park suggest sulfite availability at the $0.4-5 \mu M$ level. However, such levels of sulfite were again accessed only in hot waters (Kamyshny et al., 2014). It is not clear how compatible such conditions are with prebiotic chemistry; for example, most of the cyanosulfidic chemistries of Patel et al. (2015) and Xu et al. (2016) were conducted at room temperature $\left(25^{\circ} \mathrm{C}\right)$, and in general many molecules thought to be relevant to the origin of life, such as ribozymes, RNA, and their components, are more stable and function better at cooler temperatures (Levy and Miller, 1998; Attwater et al., 2010; Kua and Bada, 2011; Akoopie and Müller, 2016). However, for hot origin-of-life scenarios, e.g., those at deep-sea hydrothermal vents, hydrothermal systems may be compelling venues for cyanosulfidic reaction networks like that of Patel et al. (2015), reinforcing the utility of volcanism for prebiotic chemistry.

\section{Conclusion and Next Steps}

Constraining the abundances of trace chemical species on early Earth is important to understanding whether postulated prebiotic pathways which are dependent on them could have proceeded. Here, we show that prebiotically relevant levels of certain sulfidic anions are globally available in shallow, wellmixed aqueous reservoirs due to dissolution of sulfur-bearing gases that are volcanically injected into the atmosphere of early Earth. In particular, anions derived from $\mathrm{SO}_{2}$ are available at $\geq 1 \mu M$ levels in non-acidic reservoirs for $\mathrm{SO}_{2}$ outgassing rates corresponding to modern Earth and higher. During episodes of intense volcanism, like the emplacement of basaltic fields like the Deccan Traps, $\mathrm{SO}_{2}$-derived anions may be available at $\geq 1 \mathrm{~m} M$ levels for reservoirs buffered to $\mathrm{pH} \geq 7$ (e.g., the modern ocean at $\mathrm{pH}=8.2$ ) and at a temperature of $T=25^{\circ} \mathrm{C}$, though sulfite disproportionation may have ultimately limited concentrations to the $\sim 10 \mu M$ level; better constraints on sulfite disproportionation reaction rates are required to constrain this possibility. At cooler temperatures, even higher concentrations of these anions would have been available. Formation of mineral precipitate should not inhibit sulfite concentrations until $\geq 1 \mathrm{~m} M$ concentrations so long as the reservoir is not acidic, but might suppress sulfite

\footnotetext{
${ }^{14}$ We speculate that $\mathrm{HS}^{-}$-rich shallow hydrothermal systems tend to be hot because the same volcanism that supplies elevated levels of $\mathrm{HS}^{-}$also supplies elevated levels of heat.
}

levels in acidic waters. On the other hand, anions derived from $\mathrm{H}_{2} \mathrm{~S}$ would not have been available at micromolar levels across the plausible range of volcanic outgassing due to low solubility of $\mathrm{H}_{2} \mathrm{~S}$ and an unfavorable dissociation constant, and prebiotic chemistry invoking such anions must invoke local, specialized sources. Radiative transfer calculations suggest that NUV radiation will remain abundant at the planet surface for $\phi_{\mathrm{S}} \leq 1 \times 10^{11} \mathrm{~cm}^{-2} \mathrm{~s}^{-1}$ but will be suppressed for $\phi_{\mathrm{S}} \geq 3 \times 10^{11} \mathrm{~cm}^{-2} \mathrm{~s}^{-1}$; such epochs may be especially clement for surficial, UV-independent prebiotic chemistry. We applied our results to the case study of the proposed prebiotic reaction network of Patel et al. (2015). The prebiotic plausibility of this network can be improved if it can be adapted to use $\mathrm{SO}_{2}$-derived anions like $\mathrm{HSO}_{3}{ }^{-}$or $\mathrm{SO}_{3}{ }^{2-}$ instead of $\mathrm{HS}^{-}$, since the atmosphere is capable of supplying prebiotically relevant levels of the former directly but more localized sources must be invoked for adequate supply of the latter. Coupled with the potential for volcanogenic synthesis of feedstock molecules like HCN and phosphate (Zahnle, 1986; Yamagata et al., 1991), it appears that episodes of moderately intense volcanism $\left(\phi_{\mathrm{S}} \approx 1 \times 10^{11} \mathrm{~cm}^{-2} \mathrm{~s}^{-1}\right)$ might have been especially clement for cyanosulfidic prebiotic chemistry which exploits $\mathrm{SO}_{2}$-derived anions (e.g., $\left.\mathrm{HSO}_{3}{ }^{-}\right)$. Avenues for future work include simulating these scenarios experimentally and/or with a large general-purpose aqueous geochemistry code, improving measurements of the sulfite disproportionation reaction rate constant, and further photochemical modeling to improve constraints on the expected concentrations of $\mathrm{SO}_{2}$ and $\mathrm{H}_{2} \mathrm{~S}$ on early Earth.

\section{A. Atmospheric Sulfur Speciation}

We use the work of Hu et al. (2013) to connect the sulfur emission flux $\phi_{\mathrm{S}}$ to the speciation of atmospheric sulfur. Table A1 presents $\mathrm{H}_{2} \mathrm{~S}$ and $\mathrm{SO}_{2}$ mixing ratios as a function of $\phi_{\mathrm{S}}$ from $\mathrm{Hu}$ et al. (2013) (their Fig. 5, $\mathrm{CO}_{2}$-dominated atmosphere case).

\section{B. Activity Coefficient Calculation}

This appendix describes the calculation of the activity coefficients of the ions involved in equilibria reactions for $\mathrm{SO}_{2}$ and $\mathrm{H}_{2} \mathrm{~S}$.

We use the Extended Debye-Huckel theory to calculate activity coefficients $\left(\gamma_{i}\right)$ for the ions in our study. Extended Debye-Huckel theory is valid for ionic strengths up to 0.1 $M$, which is the highest ionic strength we consider, motivated by the fact that lipid vesicle formation is inhibited at ionic strengths above 0.1 $M$ (Maurer and Nguyen, 2016).

Table A1. Column-Integrated Mixing Ratios of $\mathrm{H}_{2} \mathrm{~S}$ AND $\mathrm{SO}_{2}$ AS A FunCTION OF $\phi_{\mathrm{S}}$ FROM HU $E T A L$. (2013) (Their Fig. 5, $\mathrm{CO}_{2}$-Dominated CASE)

\begin{tabular}{lll}
\hline$\phi_{\mathrm{S}}\left(\mathrm{cm}^{-2} \mathrm{~s}^{-1}\right)$ & $\mathrm{r}_{\mathrm{H}_{2} \mathrm{~S}}$ & $\mathrm{r}_{\mathrm{SO}_{2}}$ \\
\hline $3 \times 10^{9}$ & $4 \times 10^{-10}$ & $3 \times 10^{-10}$ \\
$1 \times 10^{10}$ & $1 \times 10^{-9}$ & $9 \times 10^{-10}$ \\
$3 \times 10^{10}$ & $9 \times 10^{-9}$ & $3 \times 10^{-9}$ \\
$1 \times 10^{11}$ & $5 \times 10^{-8}$ & $7 \times 10^{-9}$ \\
$3 \times 10^{11}$ & $2 \times 10^{-7}$ & $1 \times 10^{-8}$ \\
$1 \times 10^{12}$ & $7 \times 10^{-7}$ & $3 \times 10^{-8}$ \\
$3 \times 10^{12}$ & $2 \times 10^{-6}$ & $8 \times 10^{-8}$ \\
$1 \times 10^{13}$ & $9 \times 10^{-6}$ & $3 \times 10^{-7}$ \\
\hline
\end{tabular}


TABle B1. VAlues For the ION-SPecific PARAmeter $\alpha$ (Related to the Hydration Sphere of the ION) Used to Calculate Activity Coefficients

\begin{tabular}{lc}
\hline Ion & $\alpha_{\mathrm{i}}(\AA)$ \\
\hline $\mathrm{HSO}_{3}{ }^{-}$ & 4.0 \\
$\mathrm{SO}_{3}{ }^{2-}$ & 4.5 \\
$\mathrm{HS}^{-}$ & 3.5 \\
$\mathrm{~S}^{2-}$ & 5.0 \\
$\mathrm{OH}^{-}$ & 3.5 \\
$\mathrm{H}^{+}$ & 9.0 \\
\hline
\end{tabular}

Extended Debye Huckel theory states that

$$
\log \gamma_{i}=-A z_{i}^{2} \frac{I^{0.5}}{1+B \alpha_{i} I^{0.5}}
$$

where $A$ and $B$ depend on the temperature, density, and dielectric constant of the solvent (in our case water), and $\alpha_{i}$ is an ion-specific parameter. We took $A=0.5085 M^{-1 / 2}$ and $B=0.3281 M^{-1 / 2} \AA^{-1}$, corresponding to $T=25^{\circ} \mathrm{C}$; Appendix D describes the sensitivity of our analysis to this assumption. Table B1 summarizes the $\alpha_{i}$ used in our study, taken from Misra (2012). We were unable to locate a value of $\alpha_{C}$ for $\mathrm{HS}_{2} \mathrm{O}_{5}{ }^{-}$and consequently take $\gamma_{\mathrm{HS}_{2} \mathrm{O}_{5}{ }^{-}}=1$ throughout (i.e., we do not correct for its activity). Since in our analysis the supply of $\mathrm{SO}_{2}$ is not limited (the atmosphere is treated as an infinite reservoir), $\mathrm{p} K_{\mathrm{asO}_{2,3}}$ affects only the abundance of $\mathrm{H}_{2} \mathrm{SO}_{5}{ }^{-}$, which is a trace compound in our analysis (see Fig. 2).

Table B2 shows the activity coefficients for the relevant ions at the two ionic strengths considered in our study.

\section{Sensitivity of Henry's Law Constants to Salinity}

This appendix describes our assessment of the sensitivity of the Henry's law coefficients for $\mathrm{SO}_{2}$ and $\mathrm{H}_{2} \mathrm{~S}$ to salinity.

We account for the effect of salinity on $H_{G}$ using the Schumpe-Sechenov method, as outlined in Burkholder et al. (2015):

$$
\log H_{0} / H=\Sigma_{i}\left(h_{i}+h_{G}\right) * c_{i}
$$

where $H_{0}$ is the Henry's law constant in pure water, $H$ is the Henry's law constant in saline solution, $c_{i}$ is the concentration of the ion $i, h_{i}$ is an ion-specific constant, and $h_{G}$ is a gas-specific constant. $h_{G}$ is temperature dependent, via $h_{G}=h_{0}+h_{T}(T-298.15 \mathrm{~K}) . \mathrm{NaCl}$ is the dominant salt in Earth's oceans; we approximate $\mathrm{NaCl}$ as the sole source of salinity in our calculations. Table $\mathrm{C} 1$ summarizes the values of these parameters used for this study, all taken from the

Table B2. Per-Ion Activity Coefficients FOR DIFFERENT IONIC STRENGTHS

\begin{tabular}{lcc}
\hline Ion & $\mathrm{I}=0 \mathrm{M}$ & $\mathrm{I}=0.1 \mathrm{M}$ \\
\hline $\mathrm{HSO}_{3}^{-}$ & 1.0 & 0.770 \\
$\mathrm{SO}_{3}{ }^{2-}$ & 1.0 & 0.364 \\
$\mathrm{HS}^{-}$ & 1.0 & 0.762 \\
$\mathrm{~S}^{2-}$ & 1.0 & 0.377 \\
$\mathrm{OH}^{-}$ & 1.0 & 0.762 \\
$\mathrm{H}^{+}$ & 1.0 & 0.826 \\
\hline
\end{tabular}

Table C1. Parameters Used to Estimate THE DEPENDENCE OF HENRY'S LAW CONSTANTS ON [NACL]

\begin{tabular}{lcccc}
\hline Parameter & $\mathrm{H}_{2} \mathrm{~S}$ & $\mathrm{SO}_{2}$ & $\mathrm{Na}^{+}$ & $\mathrm{Cl}^{-}$ \\
\hline$H_{0}(M / \mathrm{bar})$ & 0.101 & 1.34 & - & - \\
$h_{0}\left(M^{1}\right)$ & -0.0333 & -0.0607 & - & - \\
$h_{T}\left(M^{-1}\right)$ & $0^{\mathrm{a}}$ & 0.000275 & - & - \\
$h_{i}\left(M^{-1}\right)$ & - & - & 0.1143 & 0.0318 \\
\hline
\end{tabular}

${ }^{\mathrm{a}}$ Value not found in literature search; assumed to be 0 .

compendium of Burkholder et al. (2015). We were unable to locate a value for $h_{T}$ for $\mathrm{H}_{2} \mathrm{~S}$ in our literature search, and assumed $h_{T}=0$ for this case.

The Henry's law constants for these gases as a function of $[\mathrm{NaCl}]$ at $T=298.15 \mathrm{~K}$ are shown in Fig. C1. In this study, we consider ionic strengths $I \leq 0.1 M$, corresponding to $[\mathrm{NaCl}] \leq 0.1 M$. At such levels, salinity has a negligible effect on Henry's law solubility, and we consequently neglect it in our calculations.

\section{Sensitivity of Analysis to Temperature}

This appendix describes our assessment of the sensitivity of our calculations to the temperature of the aqueous reservoir in which the equilibrium chemistry proceeds.

\section{D.1. Sensitivity of Henry's law constants to temperature}

We calculated the effect of temperature on Henry's law using the three-term empirical fit outlined in Burkholder
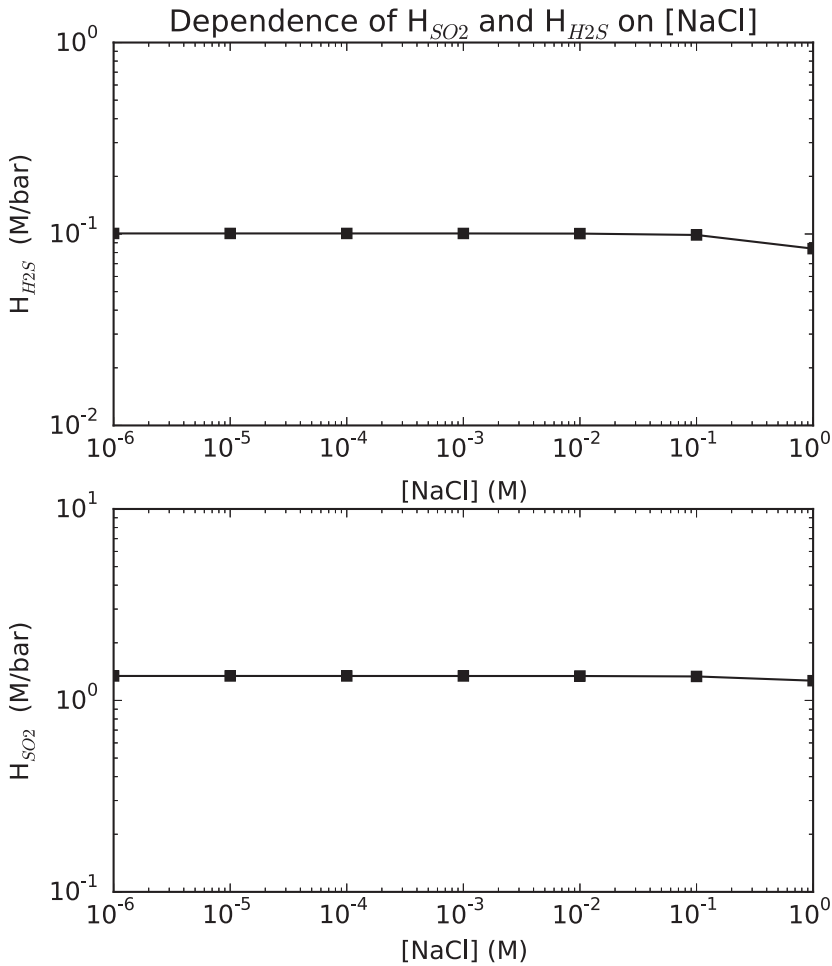

FIG. C1. Dependence of Henry's law constants for $\mathrm{H}_{2} \mathrm{~S}$ and $\mathrm{SO}_{2}$ on $[\mathrm{NaCl}]$, calculated using the formalism from Burkholder et al. (2015). $H_{\mathrm{H}_{2} \mathrm{~S}}$ and $\mathrm{H}_{\mathrm{SO}_{2}}$ are insensitive to $[\mathrm{NaCl}]$ for $[\mathrm{NaCl}]<1 M$. 
Table D1. Parameters Used to Estimate Dependence of Henry's Law Constant on Temperature

\begin{tabular}{lcc}
\hline Parameter & $\mathrm{H}_{2} \mathrm{~S}$ & $\mathrm{SO}_{2}$ \\
\hline$A$ & -145.2 & -39.72 \\
$B$ & 8120 & 4250 \\
$C$ & 20.296 & 4.525 \\
\hline
\end{tabular}

et al. (2015), that is, $\ln (H)=A+B / T+C \ln (T)$, where $H$ is in units of $M /$ atm and $A, B$, and $C$ are gas-specific coefficients of an empirical fit. The values of these coefficients for $\mathrm{H}_{2} \mathrm{~S}$ and $\mathrm{SO}_{2}$ were taken from Burkholder et al. (2015) and are summarized in Table D1. $H(T)$ for $\mathrm{H}_{2} \mathrm{~S}$ and $\mathrm{SO}_{2}$ is plotted in Fig. D1. For temperatures ranging from $0^{\circ} \mathrm{C}$ to $-50^{\circ} \mathrm{C}$ ( 273.15 to $323.15 \mathrm{~K}$ ), the Henry's law constants vary by less than a factor of 2.5 relative to their values at $25^{\circ} \mathrm{C}(293.15$ $\mathrm{K})$, which is small compared to the order-of-magnitude variations in concentration we focus on in this study. We also estimated the temperature dependence using the van't Hoff equation as outlined in Sander (2015) and obtained similar results.

\section{D.2. Sensitivity of reaction rates to temperature}

In order to assess the temperature dependence of acid dissociation $\mathrm{p} K_{\mathrm{a}}$ values, we use the van't Hoff equation:

$$
\frac{\partial\left[\ln K_{0}\right]}{\partial T}=\frac{\Delta H_{0}}{R T^{2}}
$$

where $K_{0}$ is the equilibrium constant, $T$ is temperature, $\Delta H_{0}$ is the change in enthalpy, and $R=8.314 \times 10^{-3} \mathrm{~kJ} / \mathrm{mol} / \mathrm{K}$. Solving this differential equation, assuming temperatureinvariant enthalpy of solution ${ }^{15}$, gives

$$
\ln \left(K_{2}\right)=\ln \left(K_{1}\right)+\frac{-\Delta H_{0}}{R}\left(\frac{1}{T_{2}}-\frac{1}{T_{1}}\right)
$$

With this equation, the acid dissociation constant $K_{2}$ can be estimated at a given temperature $T_{2}$, provided its value $K_{1}$ is known at a reference temperature $T_{1} . \Delta H$ is the change in enthalpy of the reaction, given by

$$
\Delta H=\sum \Delta H_{f}^{\circ}(\text { products })-\sum \Delta H_{f}^{\circ}(\text { reactants })
$$

The enthalpies of formation for the products and reactants of the first two acid dissociation reactions for $\mathrm{H}_{2} \mathrm{~S}$ and $\mathrm{SO}_{2}$ are taken from Lide (2009) and are shown in Table D2. Note that $\Delta H_{f}^{\circ}=0$ for $\mathrm{H}^{+}$, by definition. We were unable to locate an enthalpy of formation for $\mathrm{H}_{2} \mathrm{SO}_{5}{ }^{-}$and consequently are unable to calculate the temperature dependence of $\mathrm{p} K_{\mathrm{a}_{\mathrm{SO}, 3},}$. Since in our analysis the supply of $\mathrm{SO}_{2}$ is not limited (the atmosphere is treated as an infinite reservoir), $\mathrm{p} K_{\mathrm{asO}_{2,3}}$ affects only the abundance of $\mathrm{H}_{2} \mathrm{SO}_{5}{ }^{-}$, which is a trace compound in our analysis (see Fig. 2).

\footnotetext{
${ }^{15} \mathrm{We}$ expect this assumption to be reasonable because of the limited range of temperatures that are plausible for our surface aqueous reservoir scenario.
}
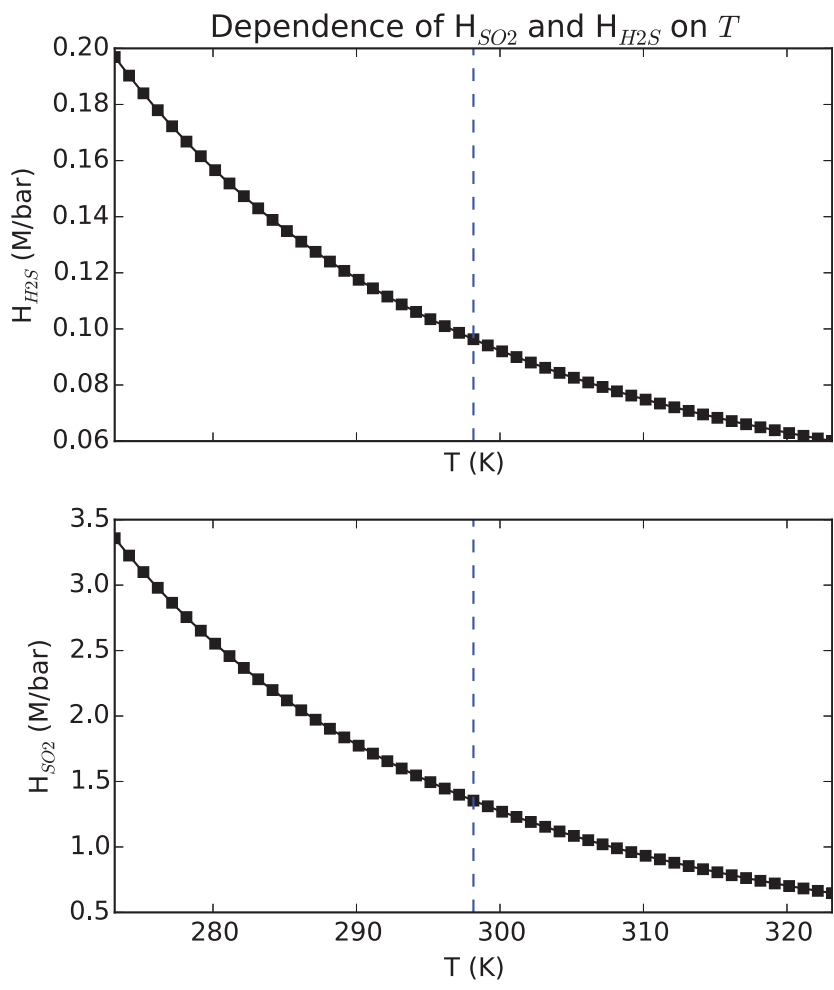

FIG. D1. Temperature dependence of Henry's law constants for $\mathrm{H}_{2} \mathrm{~S}$ and $\mathrm{SO}_{2}$, calculated using the formalism from Burkholder et al. (2015). Varying the temperature by $25 \mathrm{~K}$ relative to the reference temperature of $298.15 \mathrm{~K}$ (blue line) affects the value of $H_{\mathrm{H}_{2} \mathrm{~S}}$ and $\mathrm{H}_{\mathrm{SO}_{2}}$ by less than a factor of 2.5.

Using these values and the van't Hoff equation, we calculated the temperature dependence of the first two acid dissociation constants for aqueous $\mathrm{H}_{2} \mathrm{~S}$ and $\mathrm{SO}_{2}$. Table D3 shows these $\mathrm{p} K_{\mathrm{a}}$ values for $\mathrm{SO}_{2}$ and $\mathrm{H}_{2} \mathrm{~S}$ at $0^{\circ} \mathrm{C}, 25^{\circ} \mathrm{C}$, and $50^{\circ} \mathrm{C}$.

The variation in $\mathrm{p} K_{\mathrm{a}}$ is negligible for all reactions except the first dissociation of $\mathrm{SO}_{2} ; \mathrm{p} K_{\mathrm{asO}_{2}, 1}$ increases significantly with temperature. This implies that in non-acidic solutions, the concentrations of $\mathrm{SO}_{2}$-derived anions should decrease, and conversely that as temperature decreases they should increase.

\section{D.3. Sensitivity of activity coefficients to temperature}

Temperature dependence enters the calculation of the activity coefficients through the parameters $A$ and $B$ (see Appendix B for details). For water, at $T=0^{\circ} \mathrm{C}, A=0.4883$ $M^{-1 / 2}$ and $B=0.3241 M^{-1 / 2} \AA^{-1}$; at $T=25^{\circ} \mathrm{C}, A=0.5085 M^{-1 / 2}$

TABle D2. Enthalpies of Formation Used IN THE VAN'T HOFF EQUATION CALCULATION

\begin{tabular}{lr} 
Molecule & $\Delta \mathrm{H}_{\mathrm{f}}^{\circ}(\mathrm{kJ} / \mathrm{mol})$ \\
\hline $\mathrm{HSO}_{3}{ }^{-}$ & -626.2 \\
$\mathrm{SO}_{3}{ }^{2-}$ & -635.5 \\
$\mathrm{SO}_{2}$ & -296.8 \\
$\mathrm{HS}^{-}$ & -17.6 \\
$\mathrm{~S}^{2-}$ & 33.1 \\
$\mathrm{H}_{2} \mathrm{~S}$ & -20.6 \\
$\mathrm{H}_{2} \mathrm{O}$ & -285.8
\end{tabular}


TABle D3. $\mathrm{p} K_{\mathrm{a}}$ AT Temperatures OF $0^{\circ} \mathrm{C}, 25^{\circ} \mathrm{C}$, AND $50^{\circ} \mathrm{C}$ AND REACTION ENTHALPIES

\begin{tabular}{lcccc}
\hline & $\mathrm{T}=0^{\circ} \mathrm{C}$ & $\mathrm{T}=25^{\circ} \mathrm{C}$ & $\mathrm{T}=50^{\circ} \mathrm{C}$ & $\Delta \mathrm{H}_{r x n}^{\circ}(\mathrm{kJ} / \mathrm{mol})$ \\
\hline $\mathrm{H}_{2} \mathrm{~S}, \mathrm{p} K_{\mathrm{a} 1}$ & 7.098 & 7.05 & 7.009 & 3.0 \\
$\mathrm{H}_{2} \mathrm{~S}, \mathrm{p} K_{\mathrm{a} 2}$ & 19.81 & 19.0 & 18.31 & 50.7 \\
$\mathrm{SO}_{2}, \mathrm{p} K_{\mathrm{a} 1}$ & 1.160 & 1.86 & 2.452 & -43.6 \\
$\mathrm{SO}_{2}, \mathrm{p} K_{\mathrm{a} 2}$ & 7.051 & 7.2 & 7.326 & -9.3 \\
\hline
\end{tabular}

and $B=0.3281 M^{-1 / 2} \AA^{-1} ;$ and at $T=50^{\circ} \mathrm{C}, A=0.5319 M^{-1 / 2}$ and $B=0.3321 M^{-1 / 2} \AA^{-1}$ (Misra, 2012). From $T=0-50^{\circ} \mathrm{C}$, the activity coefficients varied by $<8 \%$ for $I \leq 0.1 \mathrm{M}$.

\section{D.4. Overall sensitivity of analysis to temperature}

We evaluated the overall sensitivity of our analysis to our assumption of $T=25^{\circ} \mathrm{C}$ by repeating our analysis at $T=0^{\circ} \mathrm{C}$ and $T=50^{\circ} \mathrm{C}$, and including the effects of temperature on Henry's law constant, the reaction $\mathrm{p} K_{\mathrm{a}}$ values, and the activity coefficients, simultaneously. Across the tested range, temperature had a negligible impact on the abundances of the $\mathrm{H}_{2} \mathrm{~S}$-derived anions but a significant impact on the abundances of the $\mathrm{SO}_{2}$-derived anions. $\mathrm{H}_{\mathrm{SO}_{2}}$ decreases with temperature, and $\mathrm{p} K_{\mathrm{aSO}_{2,1}}$ increases with temperature; both effects serve to increase the concentration of $\mathrm{HSO}_{3}{ }^{-}$and its derivatives in non-acidic $(\mathrm{pH}>2.5)$ waters. At $T=0^{\circ} \mathrm{C}, \mathrm{HSO}_{3}{ }^{-}$and $\mathrm{SO}_{3}{ }^{2-}$ concentrations are an order of magnitude higher than at $T=25^{\circ} \mathrm{C}$. Similarly, at $T=50^{\circ} \mathrm{C}, \mathrm{HSO}_{3}{ }^{-}$and $\mathrm{SO}_{3}{ }^{2-}$ concentrations are an order of magnitude lower than at $T=25^{\circ} \mathrm{C}$. Our overall conclusions are robust to these variations. However, this study does imply that significantly higher concentrations of $\mathrm{SO}_{2}$-derived anions are available to prebiotic chemistry in cooler waters, and inversely that hotter waters would have access to lower levels of $\mathrm{SO}_{2}$-derived anions.

\section{Acknowledgments}

We thank A. Levi for his insight regarding equilibrium chemistry, and D. Catling, I. Halevy, M. Claire, J. Szostak, T. Bosak, and T. Vick for answers to many questions and/or comments on the manuscript. We especially thank J. Toner for extensive discussion and feedback. We thank M. Claire for sharing sulfur aerosol cross-sections for validation purposes. This research has made use of NASA's Astrophysics Data System Bibliographic Services and the MPIMainz UV-VIS Spectral Atlas of Gaseous Molecules. S.R., Z.R.T., D.D.S., and J.D.S. gratefully acknowledge support from the Simons Foundation (S.R., Z.R.T., D.D.S.: grant no. 290360; S.R.: grant no. 495062; J.D.S.: grant no. 290362).

\section{Author Disclosure Statement}

The authors declare no competing financial interests.

\section{References}

Akoopie, A. and Müller, U.F. (2016) Lower temperature optimum of a smaller, fragmented triphosphorylation ribozyme. Phys Chem Chem Phys 18:20118-20125.

Amend, J.P. and McCollom, T.M. (2009) Energetics of biomolecule synthesis on early Earth. In Chemical Evolution II: From the Origins of Life to Modern Society, edited by L.
Zaikowski, J.M. Friedrich, and S.R. Seidel, American Chemical Society, Washington, DC, pp 63-94.

Amshoff, P., Weger, T., and Ostertag-Henning, C. (2016) $\mathrm{SO}_{2}$ solution, hydrolysis and disproportionation at geological storage conditions in the system $\mathrm{CO}_{2}-\mathrm{SO}_{2}-\mathrm{H}_{2} \mathrm{O}$. In Goldschmidt Conference Abstracts.

Attwater, J., Wochner, A., Pinheiro, V.B., Coulson, A., and Holliger, P. (2010) Ice as a protocellular medium for RNA replication. Nat Commun 1, doi:10.1038/ncomms1076.

Bada, J.L., Bigham, C., and Miller, S.L. (1994) Impact melting of frozen oceans on the early Earth: implications for the origin of life. Proc Natl Acad Sci USA 91:1248-1250.

Beckstead, A.A., Zhang, Y., de Vries, M.S., and Kohler, B. (2016) Life in the light: nucleic acid photoproperties as a legacy of chemical evolution. Phys Chem Chem Phys 18: 24228-24238.

Burkholder, J., Abbatt, J., Huie, R., Kolb, C., Orkin, V., Wine, P., Sander, S., Barker, J., Kurylo, M., and Wilmouth, D. (2015) Chemical Kinetics and Photochemical Data for Use in Atmospheric Studies: Evaluation Number 18, JPL Publication 15-10, Jet Propulsion Laboratory, California Institute of Technology, Pasadena, CA.

Claire, M.W., Sheets, J., Cohen, M., Ribas, I., Meadows, V.S., and Catling, D.C. (2012) The evolution of solar flux from $0.1 \mathrm{~nm}$ to $160 \mu \mathrm{m}$ : quantitative estimates for planetary studies. Astrophys J 757, doi:10.1088/0004-637X/757/1/95.

Claire, M.W., Kasting, J.F., Domagal-Goldman, S.D., Stüeken, E.E., Buick, R., and Meadows, V.S. (2014) Modeling the signature of sulfur mass-independent fractionation produced in the Archean atmosphere. Geochim Cosmochim Acta 141:365-380.

Cockell, C. (2000) The ultraviolet history of the terrestrial planets: implications for biological evolution. Planet Space Sci 48:203-214.

Coderre, F. and Dixon, D.G. (1999) Modeling the cyanide heap leaching of cupriferous gold ores: Part 1: Introduction and interpretation of laboratory column leaching data. Hydrometallurgy 52:151-175.

Corliss, J.B., Baross, J., and Hoffman, S. (1981) An hypothesis concerning the relationships between submarine hot springs and the origin of life on Earth. Oceanologica Acta 4(suppl.): 59-69.

Crespo-Hernández, C.E., Cohen, B., Hare, P.M., and Kohler, B. (2004) Ultrafast excited-state dynamics in nucleic acids. Chem Rev 104:1977-2020.

Cronin, T.W. (2014) On the choice of average solar zenith angle. Journal of the Atmospheric Sciences 71:2994-3003.

Deamer, D. and Damer, B. (2017) Can life begin on Enceladus? A perspective from hydrothermal chemistry. Astrobiology 17: 834-839.

Deamer, D.W. and Dworkin, J.P. (2005) Chemistry and physics of primitive membranes. In Prebiotic Chemistry, Springer, Berlin, pp 1-27.

Debye, P. and Huckel, E. (1923) On the theory of electrolytes. I. Freezing point depression and related phenomena. Physik $Z$ 24:185-206.

Delano, J. (2001) Redox history of the Earth's interior since $\sim 3900$ Ma: implications for prebiotic molecules. Orig Life Evol Biosph 31:311-341.

Farquhar, J., Bao, H., and Thiemens, M. (2000) Atmospheric influence of Earth's earliest sulfur cycle. Science 289:756-759.

Farquhar, J., Savarino, J., Airieau, S., and Thiemens, M.H. (2001) Observation of wavelength-sensitive mass-independent sulfur isotope effects during $\mathrm{SO}_{2}$ photolysis: implications for the early atmosphere. J Geophys Res 106:32829-32840. 
Forsythe, J.G., Yu, S.-S., Mamajanov, I., Grover, M.A., Krishnamurthy, R., Fernandez, F.M., and Hud, N.V. (2015) Ester-mediated amide bond formation driven by wet-dry cycles: a possible path to polypeptides on the prebiotic Earth. Angew Chem Int Ed Engl 54:9871-9875.

Grant, W. and Jones, B. (2000) Alkaline Environments, Vol. 1, Academic Press, New York, pp 126-133.

Guekezian, M., Coichev, N., Suarez-Iha, M.E.V., and de Almeida Neves, E. (1997) Stability of sulfur(IV) solutions in the presence of amines and the tendency of sulfite ions to disproportionate in stock solutions. Anal Lett 30:14231436.

Halevy, I. (2013) Production, preservation, and biological processing of mass-independent sulfur isotope fractionation in the Archean surface environment. Proc Natl Acad Sci USA 110:17644-17649.

Halevy, I. and Bachan, A. (2017) The geologic history of seawater pH. Science 355:1069-1071.

Halevy, I. and Head, J.W., III. (2014) Episodic warming of early Mars by punctuated volcanism. Nat Geosci 7:865-868.

Halevy, I., Zuber, M.T., and Schrag, D.P. (2007) A sulfur dioxide climate feedback on early Mars. Science 318:19031907.

Hall-Spencer, J.M., Rodolfo-Metalpa, R., Martin, S., Ransome, E., Fine, M., Turner, S.M., Rowley, S.J., Tedesco, D., and Buia, M.-C. (2008) Volcanic carbon dioxide vents show ecosystem effects of ocean acidification. Nature 454:96-99.

Halmer, M., Schmincke, H.-U., and Graf, H.-F. (2002) The annual volcanic gas input into the atmosphere, in particular into the stratosphere: a global data set for the past 100 years. Journal of Volcanology and Geothermal Research 115:511-528.

He, C., Gállego, I., Laughlin, B., Grover, M.A., and Hud, N.V. (2017) A viscous solvent enables information transfer from gene-length nucleic acids in a model prebiotic replication cycle. Nat Chem 9:318-324.

Higgs, P.G. and Lehman, N. (2015) The RNA world: molecular cooperation at the origins of life. Nat Rev Genet 16:7-17.

Holm, N.G. and Charlou, J.L. (2001) Initial indications of abiotic formation of hydrocarbons in the Rainbow ultramafic hydrothermal system, Mid-Atlantic Ridge. Earth Planet Sci Lett 191:1-8.

Hu, R., Seager, S., and Bains, W. (2013) Photochemistry in terrestrial exoplanet atmospheres. II. $\mathrm{H}_{2} \mathrm{~S}$ and $\mathrm{SO}_{2}$ photochemistry in anoxic atmospheres. Astrophys $J$ 769, doi: 10.1088/0004-637X/769/1/6.

Kaasalainen, H. and Stefánsson, A. (2011) Sulfur speciation in natural hydrothermal waters, Iceland. Geochim Cosmochim Acta 75:2777-2791.

Kamyshny, A., Druschel, G., Mansaray, Z.F., and Farquhar, J. (2014) Multiple sulfur isotopes fractionations associated with abiotic sulfur transformations in Yellowstone National Park geothermal springs. Geochem Trans 15, doi:10.1186/14674866-15-7.

Kasting, J.F. (1987) Theoretical constraints on oxygen and carbon dioxide concentrations in the Precambrian atmosphere. Precambrian Res 34:205-229.

Kasting, J.F. (1993) Earth's early atmosphere. Science 259: 920-926.

Kasting, J. (2014) Atmospheric composition of Hadean-early Archean Earth: the importance of CO. Geological Society of America Special Papers 504:19-28.

Kasting, J.F. and Walker, J.C.G. (1981) Limits on oxygen concentration in the prebiological atmosphere and the rate of abiotic fixation of nitrogen. J Geophys Res 86:1147-1158.
Kasting, J.F., Zahnle, K.J., Pinto, J.P., and Young, A.T. (1989) Sulfur, ultraviolet radiation, and the early evolution of life. Orig Life Evol Biosphere 19:95-108.

Kua, J. and Bada, J.L. (2011) Primordial ocean chemistry and its compatibility with the RNA world. Orig Life Evol Biosph 41:553-558.

Larowe, D.E. and Regnier, P. (2008) Thermodynamic potential for the abiotic synthesis of adenine, cytosine, guanine, thymine, uracil, ribose, and deoxyribose in hydrothermal systems. Orig Life Evol Biosph 38:383-397.

Lerman, A., Imboden, D., and Gat, J., editors. (1995) Physics and Chemistry of Lakes, $2^{\text {nd }}$ ed., Springer, Berlin.

Levy, M. and Miller, S.L. (1998) The stability of the RNA bases: implications for the origin of life. Proc Natl Acad Sci USA 95:7933-7938.

Li, W., Czaja, A.D., Van Kranendonk, M.J., Beard, B.L., Roden, E.E., and Johnson, C.M. (2013) An anoxic, Fe (II)rich, U-poor ocean 3.46 billion years ago. Geochim Cosmochim Acta 120:65-79.

Lide, D.R., editor. (2009) CRC Handbook of Chemistry and Physics, 90 ${ }^{\text {th }}$ ed., CRC Press, Boca Raton, FL.

Löhr, A., Bogaard, T., Heikens, A., Hendriks, M., Sumarti, S., Bergen, M.v., Gestel, K.C.v., Straalen, N.v., Vroon, P., and Widianarko, B. (2005) Natural pollution caused by the extremely acid crater lake Kawah Ijen, East Java, Indonesia. Environ Sci Pollut Res Int 12:89-95.

Martin, W., Baross, J., Kelley, D., and Russell, M.J. (2008) Hydrothermal vents and the origin of life. Nat Rev Microbiol 6:805-814.

Maurer, S.E. and Nguyen, G. (2016) Prebiotic vesicle formation and the necessity of salts. Orig Life Evol Biosph 46: 215-222.

McCollom, T.M. (2013) Miller-Urey and beyond: what have we learned about prebiotic organic synthesis reactions in the past 60 years? Annu Rev Earth Planet Sci 41:207-229.

McCollom, T.M. and Seewald, J.S. (2007) Abiotic synthesis of organic compounds in deep-sea hydrothermal environments. Chem Rev 107:382-401.

Meyer, B., Rigdon, M., Burner, T., Ospina, M., Ward, K., and Koshlap, K. (1982) Thermal decomposition of sulfite, bisulfite, and disulfite solutions. In Flue Gas Desulfurization, Vol. 188, edited by J.L. Hudson and G.T. Rochelle, American Chemical Society, Washington, DC, pp 113-125.

Mirzoyan, N. and Halevy, I. (2014) Kinetics of sulfite disproportionation and thiosulfate acid dissociation [abstract 1701]. In Goldschmidt Conference Abstracts.

Misra, K.C. (2012) Introduction to Geochemistry: Principles and Applications, Wiley-Blackwell, Chichester, UK.

Mojzsis, S.J., Harrison, T.M., and Pidgeon, R.T. (2001) Oxygenisotope evidence from ancient zircons for liquid water at the Earth's surface 4,300 Myr ago. Nature 409:178-181.

Morse, J.W. and Mackenzie, F.T. (1998) Hadean ocean carbonate geochemistry. Aquat Geochem 4:301-319.

Mulkidjanian, A.Y., Cherepanov, D.A., and Galperin, M.Y. (2003) Survival of the fittest before the beginning of life: selection of the first oligonucleotide-like polymers by UV light. BMC Evol Biol 3, doi:10.1186/1471-2148-3-12.

Mulkidjanian, A.Y., Bychkov, A.Y., Dibrova, D.V., Galperin, M.Y., and Koonin, E.V. (2012) Origin of first cells at terrestrial, anoxic geothermal fields. Proc Natl Acad Sci USA 109:E821-E830.

Mutschler, H., Wochner, A., and Holliger, P. (2015) Freezethaw cycles as drivers of complex ribozyme assembly. Nat Chem 7:502-508. 
Neta, P. and Huie, R.E. (1985) Free-radical chemistry of sulfite. Environ Health Perspect 64:209-217.

Novoselov, A.A., Silva, D., Schneider, J., Abrevaya, X.C., Chaffin, M.S., Serrano, P., Navarro, M.S., Conti, M.J., and de Souza Filho, C.R. (2017) Geochemical constraints on the Hadean environment from mineral fingerprints of prokaryotes. Sci Rep 7, doi:10.1038/s41598-017-04161-2.

Parkhurst, D.L. and Appelo, C.A.J. (2013) Description of input and examples for PHREEQC version 3-a computer program for speciation, batch-reaction, one-dimensional transport, and inverse geochemical calculations. Chapter 43 in Section A, Groundwater. Book 6, Modeling Techniques, Techniques and Methods 6-A43, U.S. Geological Survey, Denver, CO.

Pascal, R. (2012) Suitable energetic conditions for dynamic chemical complexity and the living state. J Syst Chem 3, doi: 10.1186/1759-2208-3-3.

Patel, B.H., Percivalle, C., Ritson, D.J., Duffy, C.D., and Sutherland, J.D. (2015) Common origins of RNA, protein and lipid precursors in a cyanosulfidic protometabolism. Nat Chem 7:301-307.

Pavlov, A.A. and Kasting, J.F. (2002) Mass-independent fractionation of sulfur isotopes in Archean sediments: strong evidence for an anoxic Archean atmosphere. Astrobiology 2: $27-41$.

Pollum, M., Ashwood, B., Jockusch, S., Lam, M., and CrespoHernández, C.E. (2016) Unintended consequences of expanding the genetic alphabet. J Am Chem Soc 138:11457-11460.

Powner, M.W., Gerland, B., and Sutherland, J.D. (2009) Synthesis of activated pyrimidine ribonucleotides in prebiotically plausible conditions. Nature 459:239-242.

Ranjan, S. and Sasselov, D.D. (2016) Influence of the UV environment on the synthesis of prebiotic molecules. Astrobiology 16:68-88.

Ranjan, S. and Sasselov, D.D. (2017) Constraints on the early terrestrial surface UV environment relevant to prebiotic chemistry. Astrobiology 17:169-204.

Ranjan, S., Wordsworth, R., and Sasselov, D.D. (2017) Atmospheric constraints on the surface UV environment of Mars at $3.9 \mathrm{Ga}$ relevant to prebiotic chemistry. Astrobiology 17: 687-708.

Rapf, R.J. and Vaida, V. (2016) Sunlight as an energetic driver in the synthesis of molecules necessary for life. Phys Chem Chem Phys 18:20067-20084.

Richter, F.M. (1985) Models for the Archean thermal regime. Earth Planet Sci Lett 73:350-360.

Rickard, D. and Luther, G.W. (2007) Chemistry of iron sulfides. Chem Rev 107:514-562.

Rios, A.C. and Tor, Y. (2013) On the origin of the canonical nucleobases: an assessment of selection pressures across chemical and early biological evolution. Isr J Chem 53:469-483.

Ritson, D. and Sutherland, J.D. (2012) Prebiotic synthesis of simple sugars by photoredox systems chemistry. Nat Chem 4: 895-899.

Robock, A. (2000) Volcanic eruptions and climate. Rev Geophys 38:191-219.

Rugheimer, S., Segura, A., Kaltenegger, L., and Sasselov, D. (2015) UV surface environment of Earth-like planets orbiting FGKM stars through geological evolution. Astrophys $J$ 806, doi:10.1088/0004-637X/806/1/137.

Ruiz-Mirazo, K., Briones, C., and de la Escosura, A. (2014) Prebiotic systems chemistry: new perspectives for the origins of life. Chem Rev 114:285-366.

Rumble, J.R., editor. (2017) CRC Handbook of Chemistry and Physics, $98^{\text {th }}$ ed., CRC Press, Boca Raton, FL.
Sagan, C. (1973) Ultraviolet selection pressure on the earliest organisms. J Theor Biol 39:195-200.

Sagan, C. and Khare, B.N. (1971) Long-wavelength ultraviolet photoproduction of amino acids on the primitive Earth. Science 173:417-420.

Sander, R. (2015) Compilation of Henry's law constants (version 4.0) for water as solvent. Atmos Chem Phys 15:4399-4981.

Sarker, P.K., Takahashi, J.-i., Obayashi, Y., Kaneko, T., and Kobayashi, K. (2013) Photo-alteration of hydantoins against UV light and its relevance to prebiotic chemistry. Adv Space Res 51:2235-2240.

Segura, A., Krelove, K., Kasting, J.F., Sommerlatt, D., Meadows, V., Crisp, D., Cohen, M., and Mlawer, E. (2003) Ozone concentrations and ultraviolet fluxes on Earth-Like planets around other stars. Astrobiology 3:689-708.

Self, S., Widdowson, M., Thordarson, T., and Jay, A.E. (2006) Volatile fluxes during flood basalt eruptions and potential effects on the global environment: a Deccan perspective. Earth Planet Sci Lett 248:518-532.

Serrano-Andres, L. and Merchan, M. (2009) Are the five natural DNA/RNA base monomers a good choice from natural selection?: a photochemical perspective. Journal of Photochemistry and Photobiology C: Photochemistry Reviews 10:21-32.

Siu, T. and Jia, C.Q. (1999) Kinetic and mechanistic study of reaction between sulfide and sulfite in aqueous solution. Ind Eng Chem Res 38:3812-3816.

Sojo, V., Herschy, B., Whicher, A., Camprubí, E., and Lane, N. (2016) The origin of life in alkaline hydrothermal vents. Astrobiology 16:181-197.

Šponer, J.E., Szabla, R., Góra, R.W., Saitta, A.M., Pietrucci, F., Saija, F., Di Mauro, E., Saladino, R., Ferus, M., Civiš, S., and Šponer, J. (2016) Prebiotic synthesis of nucleic acids and their building blocks at the atomic level-merging models and mechanisms from advanced computations and experiments. Phys Chem Chem Phys 18:20047-20066.

Springsteen, G. (2015) Reaching back to jump forward: recent efforts towards a systems-level hypothesis for an early RNA world. ChemBioChem 16:1411-1413.

Taylor, L.L., Banwart, S.A., Valdes, P.J., Leake, J.R., and Beerling, D.J. (2012) Evaluating the effects of terrestrial ecosystems, climate and carbon dioxide on weathering over geological time: a global-scale process-based approach. Philos Trans $R$ Soc Lond B Biol Sci 367:565-582.

Trail, D., Watson, E.B., and Tailby, N.D. (2011) The oxidation state of Hadean magmas and implications for early Earth's atmosphere. Nature 480:79-82.

Truesdell, A.H. and Jones, B.F. (1974) WATEQ, a computer program for calculating chemical equilibria of natural waters. Journal of Research of the U.S. Geological Survey 2: 233-248.

Urey, H.C. (1952) On the early chemical history of the Earth and the origin of life. Proc Natl Acad Sci USA 38: 351-363.

Vick, T., Dodsworth, J.A., Costa, K., Shock, E., and Hedlund, B.P. (2010) Microbiology and geochemistry of Little Hot Creek, a hot spring environment in the Long Valley caldera. Geobiology 8:140-154.

Walker, S.I., Grover, M.A., and Hud, N.V. (2012) Universal sequence replication, reversible polymerization and early functional biopolymers: a model for the initiation of prebiotic sequence evolution. PLoS One 7, doi:10.1371/journal.pone .0034166 .

Watmough, S.A. and Aherne, J. (2008) Estimating calcium weathering rates and future lake calcium concentrations in the 
Muskoka-Haliburton region of Ontario. Can J Fish Aquat Sci 65:821-833.

Wordsworth, R. and Pierrehumbert, R. (2013) Hydrogennitrogen greenhouse warming in Earth's early atmosphere. Science 339:64-67.

Xu, J., Tsanakopoulou, M., Magnani, C.J., Szabla, R., Šponer, J.E., Šponer, J., Góra, R.W., and Sutherland, J.D. (2016) A prebiotically plausible synthesis of pyrimidine $\beta$-ribonucleosides and their phosphate derivatives involving photoanomerization. Nat Chem 9:303-309.

Xu, J., Ritson, D.J., Ranjan, S., Todd, Z.R., Sasselov, D.D., and Sutherland, J.D. (2018) Photochemical reductive homologation of hydrogen cyanide using sulfite and ferrocyanide. Chemical Communications, in press.

$\mathrm{Xu}$, Y., Schoonen, M.A.A., Nordstrom, D.K., Cunningham, K.M., and Ball, J.W. (1998) Sulfur geochemistry of hydrothermal waters in Yellowstone National Park: I. The origin of thiosulfate in hot spring waters. Geochim Cosmochim Acta 62:3729-3743.

Yamagata, Y., Watanabe, H., Saitoh, M., and Namba, T. (1991) Volcanic production of polyphosphates and its relevance to prebiotic evolution. Nature 352:516-519.
Zahnle, K., Claire, M., and Catling, D. (2006) The loss of mass-independent fractionation in sulfur due to a Palaeoproterozoic collapse of atmospheric methane. Geobiology 4: 271-283.

Zahnle, K.J. (1986) Photochemistry of methane and the formation of hydrocyanic acid (HCN) in the Earth's early atmosphere. J Geophys Res 91:2819-2834.

Zeebe, R.E. and Wolf-Gladrow, D.A. (2009) Carbon Dioxide, Dissolved (Ocean), Springer, Dordrecht, the Netherlands, pp 123-127.

Address correspondence to: Sukrit Ranjan 77 Massachusetts Avenue Room 54-1719 Cambridge, MA 02139

E-mail:sukrit@mit.edu

Submitted 25 September 2017

Accepted 19 January 2018 Associate Editor: Norm Sleep 